\title{
Interpreting non-linear drug diffusion data: Utilizing Korsmeyer- Peppas model to study drug release from liposomes
}

Iren Yeeling $\mathrm{Wu}^{1}$, Sonali Bala ${ }^{1}$, Nataša Škalko-Basnet ${ }^{1}$, Massimiliano Pio di Cagno ${ }^{1,2, *}$

${ }^{1}$ Drug Transport and Delivery Research Group, Department of Pharmacy, University of Tromsø The Arctic University of Norway, Universitetsvegen 57, 9037 Tromsø, Norway.

${ }^{2}$ Department of Pharmacy, Faculty of Mathematics and Natural Sciences, University of Oslo, Sem Sælands vei 3, 0371 Oslo, Norway.

*Corresponding author.Tel.: +47 22856598; e-mail: m.p.d.cagno@farmasi.uio.no

\begin{abstract}
The aim of this work was to clarify the dynamics behind the influence of ionic strength on the changes in drug release from large unilamellar vesicles (LUVs). For this purpose, we have investigated the transport of two different model drugs (caffeine and hydrocortisone) formulated into liposomes through different types of barriers with different retention properties (regenerated cellulose and the newly introduced biomimetic barrier, Permeapad ${ }^{\circledR}$ ). Drug release from liposomes was studied utilizing the standard Franz diffusion cells. LUV dispersions were exposed to the isotonic, hypotonic and hypertonic environment (difference of $300 \mathrm{mOsm} / \mathrm{kg}$ between the initial LUVs and the environment) and experimental data treated with both linear and nonlinear (Korsmeyer-Peppas) regression models. To alter the rigidity of the liposomal membranes, cholesterol was introduced in the liposomal barriers (up to $25 \% \mathrm{w} / \mathrm{w}$ ). Korsmeyer-Peppas model was proven to be suited to analyse experimental data throughout the experimental time frame, providing important additive information in comparison to standard linear approximation. The obtained results are highly relevant as they improve the interpretation of drug release kinetics from LUVs under osmotic stress. Moreover, the findings can be utilized in the development of liposomal formulations intended for nose-to-brain targeted drug delivery.
\end{abstract}

Keywords: large unilamellar vesicles, cholesterol, drug release kinetics, osmotic stress, Permepad ${ }^{\circledR}$, Korsmeyer-Peppas model. 
Abbreviations: EE, entrapment efficiency; hypo, hypotonic environment; hyper, hypertonic environment; iso, isotonic environment; K, transport constant; LUVs, large unilamellar vesicles; $M_{t} / M_{\infty}$, fractional permeated drug; $n$, transport exponent; PBS, phosphate buffered saline; PI, polydispersity index; $\mathrm{PL}$, permeability through the liposomal bilayer; $\mathrm{R}^{2}$ adj, adjusted correlation coefficient; $\mathrm{R}_{\mathrm{B}}$, resistance to drug transport through the barrier; $\mathrm{R}$, resistance to drug transport through liposomal bilayer; $\mathrm{R}_{\mathrm{T}}$, total resistance to drug transport; SD, standard deviation; SPC, soy-






\section{Introduction}

Liposomes are lipid-based vesicles with a nanometric size range (Bangham and Horne, 1964, New, 1990). Since liposomes were first described in the 1960s (Bangham and Horne, 1964), they have been extensively studied as drug delivery systems for both hydrophilic and lipophilic drugs (Allen and Cullis, 2013, Li et al., 2019). Nasally administered liposomal drug formulations have shown promising potentials for the treatment of some brain diseases such as Alzheimer's and Parkinson's disease (Lai et al., 2013, Vieira and Gamarra, 2016). However, to achieve maximal therapeutic benefits, controlled release from the liposomes in the nasal cavity is required to obtain optimal available dose at the target site in vivo (Bourganis et al., 2018, Lai et al., 2013).

One important parameter that is often underestimated in the development of formulations for nasal drug delivery is the variability of physiological conditions at the administration site. For example, under normal physiological conditions, the nasal mucus tonicity is approximately $300 \mathrm{mOsm} / \mathrm{kg}$ (Pedersen et al., 2007). However, this value can change considerably as the nasal mucosa is rather sensitive to the external environment such as air humidity and temperature (Quraishi et al., 1998). For instance, hyperventilation in dry air can increase the human nasal tonicity up to $450 \mathrm{mOsm} / \mathrm{kg}$ (Pedersen et al., 2007). Variation in the ionic strength at the administration site is highly relevant for liposomes since they consist of semipermeable membrane, and are therefore, highly sensitive to osmosis (Bangham et al., 1967, Paula et al., 1996, Pencer et al., 2001). To predict performance of liposomes in vivo, good in vitro models that can determine the release kinetics from liposomes at the early stage of the liposomal drug development process are necessary (Solomon et al., 2017, Wacker, 2017).

Currently, there are no standard methods for studying drug release from liposomes in vitro (Nothnagel and Wacker, 2018, Solomon et al., 2017, Wacker, 2017). The proposed methods are based on separating the dissolved fraction (released drug) from the undissolved fraction (liposomal drug) (Nothnagel and Wacker, 2018). Some of the most common methods applied to liposomes are filtration, ultracentrifugation, solid phase extraction, and dialysis-based methods (Nothnagel and Wacker, 2018). The dialysis-based methods utilize the drug's diffusion across barriers to separate 
liposomal drug from released drug (Solomon et al., 2017). The liposomal formulation is placed in the donor compartment which is separated from the acceptor compartment by a barrier that can exhibit low retention (e.g. dialysis barrier) or high retention (e.g. biomimetic, biologic barrier) to drug permeation (Nothnagel and Wacker, 2018). Disadvantages regarding the dialysis-based methods are related to violation of sink condition (Solomon et al., 2017), and the fact that drug released from liposomes needs to cross an additional barrier before being quantified (Fig. 1) (Nothnagel and Wacker, 2018, Wacker, 2017). On the other hand, dialysis-based methods are convenient, cost-effective and simple. Consequently, the dialysis-based devices have been implemented into USP dissolution apparatuses (e.g. glass basket, dispersion releaser, flow-through), and used in the development of in situ methods (Nothnagel and Wacker, 2018, Solomon et al., 2017, Tang et al., 2019, Yuan et al., 2017). It has to be mentioned that the improved dialysis-based methods are still limited by the barrier properties that separates the liposomal drug from released drug. Therefore, more processing of the diffusion data is still required for correct interpretation of the release mechanism from liposomes (Jain and Jain, 2016, Wacker, 2017).

The most common way to treat diffusion data is by simple zero order mass transport kinetic (Brandl et al., 2007, Brodin et al., 2010, Nothnagel and Wacker, 2018). In both previous studies (Wu et al., 2017, Wu et al., 2019), we applied a zero order model to interpret the mass transport data. The release from liposomes was calculated by using a reference experiment of free drug solution (Wu et al., 2019). We observed that the release kinetics from liposomes were altered due to tonicity perturbations in the external environments (i.e. uneven ionic strength within inner core and external environment of liposomes). Moreover, we noticed that when the osmotic stress was applied, the drug transport profiles through regenerated cellulose barrier showed deviations from linearity, indicating possible modifications of the drug release kinetics from the liposomes over time. In such situations, the non-linear regression models for data fitting could have been applied to analyse the diffusion data (Jain and Jain, 2016).

The non-linear regression models such as Higuchi and Korsmeyer-Peppas are the two most applied mathematical models to interpret non-linear diffusion profiles (Costa 
and Sousa Lobo, 2001, Jain and Jain, 2016). The Korsmeyer-Peppas model has previously been successfully used to describe the drug release kinetics from liposomes (Haghiralsadat et al., 2018, Jain and Jain, 2016). In this study, experimental data from the dynamic dialysis studies are fitted to Eq.(1) (named the Korsmeyer-Peppas equation);

$$
\frac{M_{t}}{M_{\infty}}=K \cdot t^{n}
$$

In this equation, $M_{t} M_{\infty}$ represents the fractional permeated drug, $t$ is the time, $K$ is the transport constant (dimension of time ${ }^{-1}$ ), and $n$ is the transport exponent (dimensionless). The release constant $K$ provides mostly information on the drug formulation such as structural characteristics of the nanocarriers, whereas $n$ is important since it is related to the drug release mechanism (i.e. Fickian diffusion or non-Fickian diffusion). In the case of liposomes and assuming sink conditions, the flux of the drug (j) through a low retention barrier (e.g. regenerated cellulose) of constant thickness $(x)$ can be described by Eq.(2) (simplified Fick's first law);

$$
j=D \frac{\left(c_{d}^{0}-c_{a}\right)}{x}
$$

In this equation, $c^{0} d$ is the freely dissolved unentrapped drug concentration outside liposomes in the donor compartment, $c_{a}$ the acceptor drug concentration and $D$ is the diffusion coefficient. According to this model, the net flux of drug through the barrier is the result of two diffusion mechanisms (Fig. 1). One is the diffusion of drug molecules from the donor compartment to the acceptor compartment (experimentally measured $K$, Fig. 1). The second is the diffusion through the phospholipid bilayer of liposomes that is dependent on the liposomal release rate ( $K^{\prime}$, Fig. 1$)$. In the case where $K \approx K^{l}$, the gradient of concentration (driving force of the diffusion) should be constant, giving as result of data fitting an $n$ equal (or close) to 1 (zero-order transport kinetic, nonFickian diffusion). If $n$ is lower than $1(n<1)$, this indicates a reduced concentration gradient over time (first-order/pseudo first-order kinetic, Fig. 1). In the last scenario possible, the gradient of concentration $\left(\left(c^{0} d^{-} C_{a}\right) / x\right)$ is increasing over time, producing a positive deviation from linearity of mass transport profiles. This anomalous behaviour (associated to $n>1$ ) is generally called "super case" (Costa and Sousa Lobo, 2001, Jain and Jain, 2016). 
Under these premises, in this work, caffeine and hydrocortisone (hydrophilic and a lipophilic drug, respectively) were the chosen drugs to be formulated into large unilamellar vesicle (LUV) dispersions of controlled size and tonicity. Drug transport studies were performed employing two different types of barriers; one with a low retention (regenerated cellulose) and another with a high retention (Permeapad ${ }^{\circledR}(\mathrm{Di}$ Cagno et al., 2015)). Moreover, LUV compositions were altered by the addition of different amount of cholesterol (from 0 up to $25 \% \mathrm{w} / \mathrm{w}$ ) to increase liposomal barrier rigidity. To evaluate the influence of osmotic stress on drug release kinetics from liposomes, liposomal dispersions were exposed to environment of different ionic strengths. The obtained experimental data were analysed by the means of linear and non-linear (Korsmeyer-Peppas) regression models. The results obtained from this study might provide a new insight into the drug release mechanism from liposomes, and might be relevant for the development of liposomal drug formulations intended for nose-to-brain drug delivery.

\section{Materials and methods}

\subsection{Materials}

Caffeine, hydrocortisone, disodium hydrogen phosphate dihydrate $\left(\mathrm{Na}_{2} \mathrm{HPO}_{4} \cdot 2 \mathrm{H}_{2} \mathrm{O}\right)$, sodium chloride $(\mathrm{NaCl})$, sodium hydroxide $(\mathrm{NaOH})$, sodium dihydrogen phosphate monohydrate $\left(\mathrm{NaH}_{2} \mathrm{PO}_{4} \cdot \mathrm{H}_{2} \mathrm{O}\right)$, chloroform and methanol were purchased from Sigma-Aldrich Chemie GmbH (Steinheim, Germany). Lipoid S100 (SPC, soyphosphatidylcholine >94\%) was kindly provided from Lipoid $\mathrm{GmbH}$ (Ludwigshafen, Germany) and Permeapad ${ }^{\circledR}$ barriers from InnoME GmbH (Espelkamp, Germany).

\subsection{Preparation of phosphate buffered saline (PBS)}

PBS of $\mathrm{pH} 7.4$ and $65 \mathrm{mOsm} / \mathrm{kg}$ (namely PBS65) was prepared according to Wu et al. (2017). The measured osmolality (Semi-Micro Osmometer Model 4602, Knauer, Berlin, Germany) and $\mathrm{pH}$ (SensION ${ }^{\mathrm{TM}}+\mathrm{PH} 31 \mathrm{pH}$ meter, Hach, Barcelona, Spain) of the different PBS used in this study are represented in Table 1. To create isotonic PBS (namely PBSiso that exhibited same tonicity as the LUVs, approx. $400 \mathrm{mOsm} / \mathrm{kg}$ ), $0.05 \mathrm{~g}$ of $\mathrm{NaCl}$ was dissolved in $1 \mathrm{~L}$ of PBS65. For the preparation of hypertonic PBS (PBShyper), $0.10 \mathrm{~g}$ of $\mathrm{NaCl}$ was dissolved into $1 \mathrm{~L}$ of PBS65 (tonicity of approx. $700 \mathrm{mOsm} / \mathrm{kg}$ ). Droplets of $\mathrm{NaCl}$ dissolved in PBS65 (concentration of 
$200 \mathrm{~g} / \mathrm{L})$ were added to PBS65 in order to adjust its tonicity to PBShypo's tonicity (approx. $100 \mathrm{mOsm} / \mathrm{kg}$ ).

\subsection{Preparation of LUVs}

LUV dispersions were prepared following a method previously described (Wu et al., 2017 ). In the case of cholesterol-LUVs (11 and $25 \% \mathrm{w} / \mathrm{w}$ ), solutions of SPC/cholesterol (ratio of 9:1 w/w or $4: 1 \mathrm{w} / \mathrm{w}$ ) in chloroform were used as organic phase. LUV formulations containing caffeine were prepared by dissolving the drug in the PBS65 (2 mM), whereas in the case of hydrocortisone, the drug was dissolved in the organic phase together with lipids.

\subsection{Size, zeta potential and entrapment efficiency characterization}

LUV dispersions were diluted with PBS65 (same buffer used to prepare the LUVs) $1: 100(\mathrm{v} / \mathrm{v})$ and filtered through polyether sulfone membranes $(0.2 \mu \mathrm{m}$ pore size, VWR International, Radnor, USA) prior to size measurement. For the determination of the electrokinetic potential (ZP) on liposomes surface, LUV dispersions were diluted 1:20 (v/v) with freshly filtrated deionized water $(0.2 \mu \mathrm{m}$ pore size filter $)$ and analysis conducted at room temperature $\left(23-25^{\circ} \mathrm{C}\right)$ using the DTS1070 cell (Malvern, Worcestershire, UK). The liposomal size and ZP were measured using a Zetasizer Nano Zen $2600\left(25^{\circ} \mathrm{C}\right.$, Malvern, Worcestershire, UK) as previously described (Wu et al., 2019). To determine the entrapment efficiency (EE), drug-loaded LUVs were separated from the unentrapped drug by ultracentrifugation $\left(200000 \mathrm{~g}, 10^{\circ} \mathrm{C}\right.$, 30 min, Beckman model L8-70M with SW 60 Ti rotor, Beckman Instruments, California, USA) (Wu et al., 2019). The drug concentrations in both LUVs and supernatant (representing unentrapped drug concentration) were quantified spectroscopically (Spectra Max 190 Microplate, Spectrophotometer Molecular devices, Sunnyvale, USA) using wavelengths at 273 and $247 \mathrm{~nm}$ for caffeine and hydrocortisone, respectively. Two samples for each batch of formulations were measured minimum three times. Experiments were repeated in minimum duplicates $(n \geq 2)$.

\subsection{In vitro diffusion study}

The in vitro diffusion studies of caffeine and hydrocortisone were performed usingstandard Franz diffusion cells $\left(0.64 \mathrm{~cm}^{2}\right.$ diffusion area jacketed flat ground joint, 
PermeGear diffusion cells and systems, Hellertown, USA) following a previously described method (Wu et al., 2019). The acceptor compartment was filled with $5 \mathrm{~mL}$ PBS following Table 1. Regenerated cellulose (Visking dialysis tubing MWCO 1214 kDa, Medicell Membranes Ltd., London, UK), or alternatively, Permeapad ${ }^{\circledR}$ (InnoME GmbH, Espelkamp, Germany) was used as diffusion barrier and experiments were conducted at $35^{\circ} \mathrm{C}$ (Julabo $200 \mathrm{~F}$ heating circulator, Julabo Inc., Allentown, USA). At time zero (start of the experiment), $0.3 \mathrm{~mL}$ of PBS (same composition as acceptor buffer) was topped with $0.5 \mathrm{~mL}$ of LUV dispersion $(2 \mathrm{mM}$ total drug concentration) in the donor compartment. As reference experiments, drug solution (caffeine, $2 \mathrm{mM}$ ) or suspension (hydrocortisone, $1 \mathrm{mM}$, thermodynamic solubility) in PBS65 were also analysed. Aliquots of $0.5 \mathrm{~mL}$ were withdrawn from the acceptor compartment and replaced with equal volumes of the respective PBS (with same tonicity) every 30 min over a period of 4 hours.

\subsection{Data analysis}

\subsubsection{Resistance to drug transport determination $(R)$}

The resistance to drug transport through liposomal bilayer $\left(R_{L},\right)$ was calculated according to Wu et al. (2019). In brief, the initial part of diffusional curves (up to 2.5 hours) was used to calculate the drug flux (j) through the diffusion barrier, which was supposed to be constant during the experiment since the sink conditions were kept. The apparent permeability $(P)$ was determined by normalizing the flux over the total initial concentration $\left(c_{d}\right)$ (see Eq.(3):

$$
P=\frac{j}{c_{d}}
$$

The resistance to drug transport through liposomal bilayer $\left(R_{L}\right)$ (i.e. the reciprocal function of permeability through the liposomal bilayer, $\left.1 / P_{L}\right)$ was calculated from the total resistance to drug transport $\left(R_{T}\right.$, measured in the liposomal dispersion experiments) and from the resistance to drug transport through the barrier $\left(R_{B}\right.$, measured in drug solution experiments) by Eq.(4):

$$
R_{L}=R_{T}-R_{B}
$$

2.6.2 Non-linear regression analysis (Korsmeyer-Peppas model) 
Drug transport constants $(K)$ and transport exponents $(n)$ of the different liposomal formulations were determined by fitting of the in vitro diffusion data to the KorsmeyerPeppas equation (see Eq.(1)) using the add-in DDSolver program (China Pharmaceutical University, Nanjing, China). Microsoft Office Excel (Microsoft Corporation, Redmond, USA) was used as built-in module of the DDSolver. The $K$ and $n$ were determined in the range of $M_{t} / M_{\infty} 0-60 \%$ (Costa and Sousa Lobo, 2001).

\subsection{Stability study}

LUVs containing 0,11 and $25 \% \mathrm{w} / \mathrm{w}$ cholesterol were prepared for both model drugs (caffeine and hydrocortisone) in duplicates $(n=2)$ as described in section 2.3. Each batch was divided into two aliquots and stored in the fridge $\left(\right.$ at $\left.6^{\circ} \mathrm{C}\right)$ and at room temperature (at $22^{\circ} \mathrm{C}$ ) away from light sources for 65 days in clear polypropylene tubes (VWR ${ }^{\circledR}$ High-Performance centrifuge tubes, VWR International, Radnor, USA). Samples were periodically withdrawn ( 72 hours, 14,35 and 65 days after preparation) and analysed. The stability of liposomal dispersions was evaluated in terms of tonicity, vesicle size distribution, ZP and EE (analysis performed as described in section 2.2 and 2.4). Each sample was measured minimum four times.

\subsection{Statistical data evaluation}

Student's $t$-test was used to determine the significance of difference between means of different data sets. Differences were considered significant for $p \leq 0.050$.

\section{Results}

\subsection{Liposome characterization}

The general characteristics of liposomes used in the in vitro study are presented in Table 1 and 2. The LUV dispersions exhibited total initial tonicity of around $400 \mathrm{mOsm} / \mathrm{kg}$ (Table 1). The mean sizes of liposomes were between 236 and $374 \mathrm{~nm}$ (Table 2). Incorporation of cholesterol into the LUVs increased the mean sizes and polydispersity for caffeine-LUVs ( $p \leq 0.010$ and 0.001 , respectively), and similarly for hydrocortisone-LUVs with $25 \% \mathrm{w} / \mathrm{w}$ cholesterol ( $\mathrm{PI}, p=0.000$ ). All LUVs exhibited almost neutral surface charges. The EE was approximately $11 \%$ for caffeine-LUVs and considerably higher for hydrocortisone-LUVs (51-68\%). The EE decreased significantly with increased amount of incorporated cholesterol especially for hydrocortisone-LUVs $(p \leq 0.001)$. 


\subsection{In vitro diffusion study}

\subsubsection{Drug diffusion studies}

In Fig. 2, the diffusion profiles of caffeine and hydrocortisone in aqueous solution as well as in liposomal dispersions ( $0 \% \mathrm{w} / \mathrm{w}$ cholesterol) are reported for both regenerated cellulose and Permeapad ${ }^{\circledR}$ barriers. As it can be seen, the drug diffusion profiles through the different barriers varied accordingly to the drug used; the formulation (aqueous solution or liposomal dispersion) and the barrier (regenerated cellulose or Permeapad ${ }^{\circledR}$ ). Specifically, the amount of diffused drug was significantly higher for caffeine than for hydrocortisone for both barriers. For both drugs, the total amount of diffused drug after 2.5 hours was significantly higher $(p<0.000)$ from solution in comparison to LUV dispersion when regenerated cellulose was employed as the barrier (Fig. 2 a, $49 \pm 1$ vs $35 \pm 2 \%$ for caffeine and $40 \pm 3$ vs $16 \pm 3 \%$ for hydrocortisone, respectively). Similarly, the total amount of accumulated hydrocortisone in the acceptor medium was significantly higher for drug solutions in comparison to the liposomal formulations (cumulative diffused after 2.5 hours, $9 \pm 2$ vs $6 \%, p=0.004$ ) when Permeapad ${ }^{\circledR}$ was employed as barrier (Fig. 2b right). Interestingly, when Permeapad ${ }^{\circledR}$ was employed (Fig. 2b, lower-left), the amount of caffeine accumulated in the acceptor medium from solution and liposomal dispersion was the same.

\subsection{2 $R_{L}$ under the influence of changed external environments}

In Fig. 3, the resistances to drug transport through liposomal bilayer $\left(R_{L}\right)$ are reported for all the formulations prepared, for both drugs (caffeine in Fig. 3a and hydrocortisone in Fig. 3b, respectively) and two different types of barriers (regenerated cellulose and Permeapad ${ }^{\circledR}$ ). From these data, it appeared that the ionic strength of external environment had a remarkable impact on $R_{L}$. Specifically, $R_{L}$ was lowest when caffeine-LUVs were exposed to hypotonic environments, medium in isotonic and significantly higher level for hypertonic environment (Fig. 3a). For hydrocortisone-LUVs (Fig. $3 \mathrm{~b}$ ), the $R_{L}$ values were considerably higher in comparison to the caffeine-LUVs in all circumstances. Similarly to caffeine-LUVs, the $R_{L}$ was found to be lower for hypotonic/isotonic environment and significantly $(p<0.050)$ higher in hypertonic environment. The incorporation of cholesterol into the liposomal membrane seemed not to significantly affect $R_{L}$ of hydrocortisone, whereas, for 
caffeine, a trend indicating reduction of $R_{L}$ with growing concentration of cholesterol was observed (white bars). The employment of a biomimetic barrier such as Permeapad $^{\circledR}$ (grey bars) resulted in a slight reduction in $R_{L}$ absolute values for caffeine in comparison to regenerated cellulose even though the trend at different external environmental tonicity was respected. The same was observed for hydrocortisone, but in this case, a significant reduction of $R_{L}$ was observed with increasing concentration of cholesterol (Fig. 3a-b).

\subsubsection{Non-linear data fitting using Korsmeyer-Peppas model}

The in vitro diffusion data obtained in this study were fitted according to the Korsmeyer-Peppas equation, Eq.(1). For all data sets, the correlation coefficient $\left(R^{2}\right)$ was rather high (min. 0.96 up to 1.00 , data are shown in supplementary material, Fig.A.1-2) indicating a good correlation within experimental data and Eq.(1). From the data fitting, the transport constants (K, Fig. 4) and transport exponents ( $n$, Fig. 5 ) were determined. The $K$ values were much higher for caffeine (ranged between 8 and 25, Fig. 4a) in comparison to hydrocortisone (from 1 to 8 , Fig- 4b). It is worth mentioning that $K$ values were significantly different for regenerated cellulose (white bars) and Permeapad ${ }^{\circledR}$ (grey bars) and these differences were higher for hydrocortisone than for caffeine.

As already observed for $R_{L}$, a clear correlation between $K$ and environmental ionic strength was found. Specifically, the higher ionic strength in the external environment, the lower were the $K$ value (Fig. 4, 0\% w/w cholesterol). This phenomenon was more evident when using regenerated cellulose (white bars) as a barrier rather than Permeapad ${ }^{\circledR}$ (grey bars). In fact, no significant difference was determined in $K$ values between the hypotonic and isotonic environments employing Permeapad $^{\circledR}$ as barrier for both drugs. Interestingly, the experiments carried out on the regenerated cellulose barrier maintained a similar trend for caffeine-LUVs, even though increasing amounts of cholesterol were incorporated into LUV's lipid bilayer (Fig. 4a, 0-25\% w/w cholesterol). Differently, hydrocortisone seemed to somehow be less affected to the environmental ionic strength by the presence of cholesterol in the liposome's membrane (Fig. 4b, 0-25\% w/w cholesterol).

The $n$ values determined for caffeine-LUVs using regenerated cellulose as barrier at all tonicity conditions (Fig. 5a, white bars) ranged between 0.74-0.92. The $n$ in hypotonic environment was significantly $(p \leq 0.001)$ and consistently lowest in 
comparison to both isotonic and hypertonic values (Fig. 5a). For the caffeine-LUV experiments carried out with biomimetic Permeapad ${ }^{\circledR}$ barrier (Fig. 5a, grey bars), $n$ values were closer to 1 , ranging between $0.83-0.97$. For hydrocortisone-LUVs (Fig. 5b), $n$ values were generally higher than caffeine-LUVs and in case of Permeapad ${ }^{\circledR}$, they were even superior than 1 . Moreover, an increasing trend in $n$ values with increased cholesterol amount was detected employing regenerated cellulose. This trend was not evident for Permeapad ${ }^{\circledR}$ where the highest $n$ values were detected at $11 \% \mathrm{w} / \mathrm{w}$ cholesterol.

\subsection{Liposomal stability}

The stability data obtained for the different liposomal dispersions stored at two different temperatures $\left(6^{\circ} \mathrm{C}\right.$ and $\left.22^{\circ} \mathrm{C}\right)$ are reported in Table 3 . As it can be seen, the tonicity of all the LUV dispersions were relatively stable over the 65 days period. The mean sizes and PI of caffeine-LUVs were relatively stable when stored up to 65 days at $6^{\circ} \mathrm{C}$. The caffeine-LUVs formulations stored at room temperature $\left(22^{\circ} \mathrm{C}\right)$ exhibited significant shifts in size distribution to smaller sizes $(p \leq 0.016)$ and narrower PI ( $p \leq 0.031$ ) after approx. 14 days for the formulations with 0 and $11 \% \mathrm{w} / \mathrm{w}$ cholesterol. For the hydrocortisone-LUVs, the mean sizes and PI varied quite remarkably at both storage temperatures.

All LUV dispersions exhibited rather neutral zeta potentials right after formation, but became significantly more negative $(p<0.05)$ after storage. For the caffeine-LUVs, the increase in ZP was more significant for the samples stored at $22^{\circ} \mathrm{C}$, especially for the LUVs with no cholesterol (change up to $40 \mathrm{mV}$ ). For the hydrocortisone-LUVs, the samples stored in the fridge $\left(6^{\circ} \mathrm{C}\right)$ exhibited significant variation in $\mathrm{ZP}$ as well as those stored at room temperature $(p \leq 0.050)$. However, in this case, the ZP changes were rather small in magnitude (maximum variation of $5 \mathrm{mV}$ ).

The EE of caffeine-LUVs with various amount of cholesterol incorporated in the phospholipid bilayer $(0,11$ and $25 \% \mathrm{w} / \mathrm{w})$ showed a mean EE of $13 \%$ and maximum variation of $6 \%$ during a period of 65 days of storage at $6^{\circ} \mathrm{C}$. Surprisingly, when the same formulations were stored at $22^{\circ} \mathrm{C}$, increase of EE up to 40,30 and $19 \%$ could be found for caffeine-LUVs with 0,11 and $25 \% \mathrm{w} / \mathrm{w}$ cholesterol, respectively. Those results indicated that the liposomal integrity probably changed during storage and for these reasons, as an additive information, pictures of all the different LUV dispersions prepared for the stability study were taken at 65 days to better discriminate 
differences in the sample appearance (see supplementary material, Fig.B.1). As it can be seen, the visual perception of caffeine-LUVs dispersions with $0 \% \mathrm{w} / \mathrm{w}$ cholesterol stored at $22^{\circ} \mathrm{C}$ had a more transparent/opaque colour than those stored at $6^{\circ} \mathrm{C}$ with a more white colour (Fig.B.1a, upper-right compared to upper-left). On the contrary, the hydrocortisone-LUVs $(0-25 \% \mathrm{w} / \mathrm{w}$ cholesterol) showed more stable EE with a maximum variation of $4 \%$ (Table 3 ). These results emphasize the relevance of investigating LUV dispersion's stability as changes in size, surface charge and drug entrapment might have an impact on the drug release kinetics from the liposomes.

\section{Discussion}

\subsection{Liposome characterization}

LUV dispersions used in this work were prepared aiming to be suited for nasal delivery. For optimal transport through the nasal epithelium, the vesicles should exhibit a size of 10-400 nm, neutral ZP and toncity around 300 mOsm (Bourganis et al., 2018, Homer et al., 2000, Illum, 2007, Ohwaki et al., 1987). LUVs' tonicity, sizes, $\mathrm{PI}, \mathrm{ZP}$ and EE were found to be in the same order of magnitude as those employed in previous studies (Wu et al., 2019).

As expected, the incorporation of the neutrally charged cholesterol into the lipid bilayer (consisting of neutrally charged SPC) did not induce any significant change in the surface charge of the liposomes.

In comparison to hydrocortisone-LUVs, the sizes and PI of caffeine-LUVs, were more affected by the cholesterol incorporation in the phospholipid bilayer, which might be related to the drugs localization inside the LUVs (Briuglia et al., 2015, Leite et al., 2018).

The incorporation of cholesterol into liposomal membranes significantly affected the EE of hydrocortisone, whereas the caffeine-LUVs were not affected. This might be explained by the different affinity of drugs for the liposomal bilayer (Di Cagno and Stein, 2019) and cholesterol's affinity for the lipid bilayer. In fact, the negative effect of cholesterol on EE for lipophilic compounds is well-documented (Ali et al., 2010, Mohammed et al., 2004). From the obtained results, it was evident that cholesterol prevented, to a certain degree, hydrocortisone embedding into the liposomal bilayers by reducing the space available for hydrocortisone (Table 2). 


\subsection{In vitro diffusion study}

The current methods used to determine the release from liposomes are the filtration, ultracentrifugation, solid phase extraction and dialysis-based methods. The filtration and ultracentrifugation are two methods that with the help of mechanical forces separate the nanocarriers from the released drug. However, these methods are not suitable for easily deformable nanocarriers such as liposomes, as the separation procedure might disrupt the nanocarrier leading to overrated release (Solomon et al., 2017). For this reason, solid phase extraction is considered to be a more gentle method, and has been successfully applied to separate free drug from liposomes (Xie et al., 2018). However, some of the limitations with this method are that it is not suitable for all types of release medium, and is dependent on the medium composition (i.e. bile salts, ions, proteins), therefore the efficiency of separation can be influenced (Nothnagel and Wacker, 2018). Probably that is why the dialysis-based methods are more favoured, and in this study, we used the classical Franz diffusion cell set up to monitor the release from liposomes because of its convenience, cost-effectiveness and simplicity.

\subsubsection{Drug diffusion from drug solution and drug-loaded LUVS}

The dialysis-based method used in this study allowed us to quantify the amount of drug that diffused through a diffusion barrier. However, this method does not measure the direct release from the liposomal carrier. For correct interpretation, it has been proposed to use reference experiment of free drug solution (Wacker, 2017). For this reason, we have presented here the drug diffusion profiles from solution and LUVs through two different diffusion barriers.

The regenerated cellulose barrier is highly permeable to small and neutrally charged molecules and the drug diffusion rate through the barrier is highly controlled by the drug concentration gradient between the both sides of the barrier (Bartels et al., 2005, Benavente, 1984, Nothnagel and Wacker, 2018). On the other hand, the biomimetic Permeapad ${ }^{\circledR}$ barrier consists of a lipid layer in between two support sheets (Di Cagno and Bauer-Brandl, 2014). In contact with aqueous solution, the lipid layer is assumed to create tightly packed vesicles mimicking the structure of biological membranes (Di Cagno et al., 2015). In other words, the Permeapad ${ }^{\circledR}$ barrier represents a biomimetic barrier capable of discriminating drug permeability according to the physicochemical property of drug molecules. Consequently, the drug 
distribution coefficient at neutral $\mathrm{pH}\left(\log \mathrm{D}_{7.4}\right)$ plays a key role in the net drug mass transport through the barrier (Brandl et al., 2007, Nothnagel and Wacker, 2018). As represented in Fig. 2, the total amount of diffused drug from caffeine formulations was much lower (37-57\% according to the formulation tested) when studied with Permeapad ${ }^{\circledR}$ in comparison to regenerated cellulose barriers (Fig. 2a-b). On the other hand, for hydrocortisone formulations, a reduction of $63-78 \%$ could be observed. As expected, hydrocortisone was more retained by Permeapad ${ }^{\circledR}$ in comparison to caffeine, due to its higher lipophilicity $\left(\log \mathrm{D}_{7.4}\right.$ of 1.6 for hydrocortisone in comparison to 0.0 for caffeine) (Zhu et al., 2002).

As reported in previous studies (Di Cagno et al., 2015, Fadda et al., 1998, Wu et al., 2017, Wu et al., 2019), the drug diffusion rate was lower for liposomal dispersions in comparison to drug solutions when analysed on regenerated cellulose barrier (Fig. 2). Surprisingly, this difference was not evident when Permeapad ${ }^{\circledR}$ was employed. This interesting finding indicates that, when biomimetic barrier was employed, the differences in drug transport properties within different formulations were reduced if not annulled. This can be by reason of the biomimetic barrier is the limiting step of the permeation in this case, reducing the impact of the formulation on the total drug transport kinetic. However, for hydrocortisone, a small difference between diffusion from drug solution or liposomal formulation was detectable, indicating that this phenomena is highly drug dependent.

To evaluate better the liposomal bilayer's contribution to changed drug diffusion profiles across the different barriers, we decided to report the $R_{L}$ as shown in the next sections. We also incorporated various amount of cholesterol into the liposomal bilayer (0-25\% w/w) to study the relationship between liposomal rigidity and drug release. Moreover, we exposed the LUVs to different environmental tonicity to see if this could affect the drug release.

\subsubsection{Influence of cholesterol on $R_{L}$}

Liposomes containing hydrophilic molecules might experience leakage due to cholesterol induced lipid bilayer reconstruction (Briuglia et al., 2015, Schullery, 1977). The effect cholesterol has on the SPC liposomes and the release properties from them can be translated from the calculated $R_{L}$ values. The decreasing $R_{L}$ values indicated that more drug was diffusing out of the nanocarrier. In agreement with the literature, the $R_{L}$ was found decreasing for both caffeine- (Fig. 3a) and 
hydrocortisone-LUVs (Fig. 3b) when the amount of incorporated cholesterol increased from 0 to $25 \% \mathrm{w} / \mathrm{w}$.

On the other hand, it has also been argued that liposomes containing cholesterol should exhibit higher liposomal bilayer rigidity and the resistance to drug transport $\left(R_{L}\right)$ should increase as compared to liposomes made of plain SPC (Leite et al., 2018, Milon et al., 1986). Surprisingly, the findings from this study seem to deviate from the reported literature. This fact can be explained by the variations of unentrapped drug concentration in the different formulations. As shown in Table 2, the hydrocortisone entrapment was strongly affected by the presence of cholesterol, whereas this was not found for the caffeine-LUVs. Specifically, only minimal changes in the unentrapped drug concentration for caffeine-LUVs with various amount of cholesterol could be measured (ranged between 1758 to $1773 \mu \mathrm{M}$ ), whereas hydrocortisone-LUVs showed unentrapped drug concentrations of 798,838 and $992 \mu \mathrm{M}$ for 0,11 and $25 \% \mathrm{w} / \mathrm{w}$ cholesterol, respectively. The higher the unentrapped drug concentration, the higher the concentration gradient (Eq. 2) and therefore the flux through the membrane. It should be underlined that these data are in agreement with previous reports of supersaturation induced by liposomal formulations (Di Cagno and Luppi 2013).

\subsubsection{Influence of ionic strength on $R_{L}$}

Early works have shown that large unilamellar vesicles are susceptible to osmotic stress induced vesicle size changes (Mui et al., 1993, Sun et al., 1986). Liposomes have the tendency to swell when exposed to hypotonic environments. As a result of the swelling, the liposomal membrane becomes thinner and this can contribute to increased release from liposomes (i.e. reduced $R_{L}$ ) (Ahumada et al., 2015, Alam shibly et al., 2016, Polozov et al., 2001). On the contrary, when liposomes are exposed to hypertonic environments, liposomes shrink and the liposomal membrane might become less permeable to drug permeation (i.e. higher $R_{L}$ ) (Ahumada et al., 2015, Fujiwara and Yanagisawa, 2014, Ohno et al., 2009). Our results were in agreement with the literature (Ahumada et al., 2015, Alam shibly et al., 2016, Fujiwara and Yanagisawa, 2014, Ohno et al., 2009, Polozov et al., 2001). For almost all caffeine-LUV formulations, the $R_{L}$ was significantly lower in hypotonic environment and highest for the hypertonic environment (Fig. 3a). Similar trend was also observed for hydrocortisone to a lower extent (Fig. 3b). 
As it can be seen in Fig. 3a, the $R_{L}$ values were negative for the caffeine-LUVs when experiments were conducted using Permeapad ${ }^{\circledR}$ barriers. This result indicate that, in some cases, linear regression applied for data treatment and $R_{L}$ calculation, even though feasible, might lead to incomplete- or miss-interpretation of the data. This might be due to the experimental set up conditions where the drug release is highly influenced by the equilibrium across the diffusion barrier.

One upcoming apparatus for drug release study from liposomes is the flow-through USP 4 (Tang et al., 2019, Yuan et al., 2017). This apparatus provides continuous flow of the release medium into a cell containing the drug formulation. The release medium with instant released drug is then pumped through a separation device (e.g. dialysis-based device) to remove liposomal drug, and the collected sample can be measured in situ at predetermined time points. The advantages with this method include its continuous renewal of the release medium, and the easily varied medium composition according to the solubility of the drug. Moreover, the apparatus can easily adjust variables such as temperature, flow rate, and detection wavelength. Sample measurements can be automatic, and relatively little manual work is required. However, due to the fact that relatively few companies develop the flowthrough cells, and the complexity of the apparatus, this method is still not mainstream (Solomon et al., 2017).

The main purpose of this study was not to improve the experimental set up conditions, but to better interpret the obtained diffusion data collected from available equipment in our laboratory. It has to be mentioned that even though the flowthrough USP 4 drug release assay might be a superior method, and has shown some promising results for studying release from liposomes (Tang et al., 2019, Yuan et al., 2017), this method is still limited by the barrier properties that separates the liposomal drug from released drug. Therefore, more processing of the diffusion data is still required for correct interpretation of the release mechanism from liposomes (Jain and Jain, 2016, Solomon et al., 2017, Wacker, 2017).

Two of the most common mathematical methods used to study non-linear diffusion profiles are the Higuchi and Korsmeyer-Peppas model. In this study, we investigated the diffusion data employing the Korsmeyer-Peppas model.

\subsubsection{Data fitting to the Korsmeyer-Peppas model}


Since the aim of this study was to investigate the contributing alterations in liposomal bilayer properties relevant for drug release, the Korsmeyer-Peppas model was chosen due to its ability to provide the descriptive information on both release kinetics and mechanism of drug release. It should be underlined that the data we have been fitting to the model refer to the diffusion through low retention/high retention barriers, however, the data also reflect (as described in Fig. 1) the release kinetics from the nanocarriers.

The parameter $K$ indicated the constant drug transport that can be seen intuitively as directly proportional to the drug release kinetics from LUVs. In fact, higher $K$ indicated faster drug release. On a contrary, lower value of $K$ indicated a low transport kinetic and therefore poor drug release from nanocarriers. Interestingly, caffeine-LUVs generally expressed higher $K$ values in comparison to hydrocortisone-LUVs (Fig. 4a and $4 b)$. This was expected, since caffeine is known for its high permeability through phospholipid barriers (Di Cagno et al., 2015, Flaten et al., 2006). It should be underlined that $K$ and $R_{L}$ were in rather good agreement; the higher the $R_{L}$, the lower value of $K$, and vice versa. As seen before for $R_{L}, K$ also seemed to be highly influenced by changes in the ionic strengths of external environments. Specifically, the higher the increase in the external ionic strength (consequently shrinkage of liposomes) the $K$ became lower, indicating a clear reduction of drug release from liposomes.

The $K$ changed more drastically in response to the environment when the regenerated cellulose barriers were employed in comparison to the Permeapad ${ }^{\circledR}$ barriers. This implies that, when biomimetic barriers were employed (i.e. higher retention barrier), the drug formulation plays a minor role in the net final drug transported through the barrier. This was also an interesting finding, highlighting the fact that dialysis barriers were extremely efficient to measure formulation kinetics but not necessarily predictive for in vitro-in vivo correlations.

The advantage with the non-linear fitting approach was that a larger part of the experimental data was efficiently fitted $\left(M_{t} / M_{\infty}\right.$ up to $\left.60 \%\right)$ and seemed to better represent the drug diffusion kinetics from liposomes. Moreover, using this data treatment approach, there was no need to measure reference sample (i.e. drug solution). The application of Korsmeyer-Peppas model resulted in the time-efficient and precise method for interpreting diffusion data from nanocarriers. 
Under the influence of osmotic stress, the drug release kinetics of both caffeine (Fig. 4a) and hydrocortisone (Fig. 4b) from liposomes exhibited less variations in $K$ when cholesterol was incorporated in the bilayers ( 0 vs $25 \% \mathrm{w} / \mathrm{w}$ ). The more stable $K$ values in different environmental ionic strengths indicated that the liposomal sensitivity to osmotic influences decreased. Possible explanation could be that cholesterol embedment into the liposomal bilayer decreases its flexibility (Leite et al., 2018).

The advantage with the Korsmeyer-Peppas model was the mechanistic considerations this model permitted, describing the drug release mechanism from liposomes by providing the transport exponent, $n$. In order to have a Fickian diffusion process, when no boundaries are present, $n$ should be equal to 0.5 , whereas values of $n$ between 0.5 and 1 indicates non-Fickian diffusion and are indications of boundary region affecting the passive drug diffusion (Costa and Sousa Lobo, 2001). For the regenerated cellulose experiments (Fig. 5), $n$ values for caffeine were always lower than 1. The lowest value of $n$ measured for the diffusion of caffeine was in hypotonic environment $(0.75-0.78)$ when the lipid bilayers should be the most stretched and therefore with the lowest resistance (Fig. 3) (Ahumada et al., 2015, Alam shibly et al., 2016, Polozov et al., 2001). Interestingly, when liposomes were exposed to isotonic and hypertonic environments, the $n$ value increased remarkably (between 0.83 and 0.92). This variation in $n$ indicated that the diffusion of caffeine was moving even further from a Fickian behaviour. This can be very well explained by the increasing resistance of caffeine transport through liposomal bilayers induced by vesicles' shrinkage (Ahumada et al., 2015, Fujiwara and Yanagisawa, 2014, Ohno et al., 2009). Considering the experiments with regenerated cellulose barrier, in the case of hydrocortisone, $n$ values were higher than for caffeine ranging between 0.86 and 0.98 . This finding suggests that hydrocortisone was from the start diffusing in a more controlled manner from the liposomal bilayer. The release profile of hydrocortisone seemed to be less affected by the changes in ionic strengths of liposomal surrounding environment (as observed in previous studies (Wu et al., 2017, Wu et al., 2019)).

For the Permeapad ${ }^{\circledR}$ experiments, the $n$ were found relatively more stable and were less affected by changes in the external environment of LUVs. As mentioned

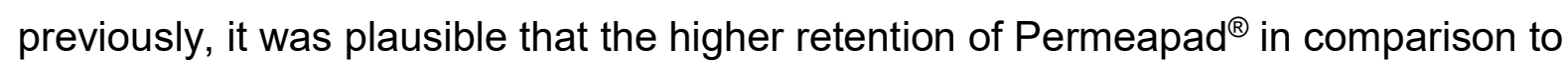
regenerated cellulose overrules the liposomal effect $\left(K<<K^{\prime}\right)$. 


\subsection{Formulation stability}

All LUV formulations prepared in this study retained a stable tonicity upon storage at both 6 and $22^{\circ} \mathrm{C}$ (Table 3 ). Stable tonicity is an important parameter considering the overall stability of liposomal suspensions (Grit and Crommelin, 1993).

The more stable LUV dispersions in terms of size, PI and EE were the ones stored at 6 rather than at $22^{\circ} \mathrm{C}$, as expected. Moreover, low temperatures $\left(4-6^{\circ} \mathrm{C}\right)$ are the recommendable storage conditions for liposomes (Grit and Crommelin, 1993). Instability of LUV dispersions in terms of drug loading can be described as the leakage of originally-associated liposomal content during storage. As expected, the hydrocortisone-LUVs exhibited stable EE up to 65 days at both 6 and $22^{\circ} \mathrm{C}$ independently of the amount of incorporated cholesterol. Surprisingly, the EE of caffeine-LUVs stored at $22^{\circ} \mathrm{C}$ seemed to increase over time. Similar increase in drug loading upon storage has been reported for other small hydrophilic compound such as rivastigmine (MW of $250 \mathrm{~g} / \mathrm{mole}$ (Pubchem, 2019c)). Caffeine has MW of $194 \mathrm{~g} / \mathrm{mole}$ (Pubchem, 2019a). In the study carried out by Arumugam et al., an increase in EE of rivastigmine in liposomes was measured after 3 months of storage in comparison to freshly prepared drug-loaded liposomes (Arumugam et al., 2008). This might be an indication that the liposomal bilayer structure is permitting drug to pass through the liposomal membrane considering that we did not remove the unentrapped drug from the formulation. Analysing the samples visually, the caffeineLUV dispersions without cholesterol had a more transparent/opaque colour in comparison to the formulations with cholesterol $(11-25 \% \mathrm{w} / \mathrm{w})$. The increase in the EE for those formulations were probably due to drug migration to equilibrium in the samples as if the liposomal bilayers were no longer present. However, it could be observed that the changes in caffeine entrapment were not evident when cholesterol was in the lipid bilayer; it is well known that cholesterol stabilizes phospholipid bilayers (Briuglia et al., 2015, Grit and Crommelin, 1993).

Taking into account all the variables measured, LUVs with $11 \% \mathrm{w} / \mathrm{w}$ cholesterol seemed to be the most stable formulation and exhibited suitable storage profiles in terms of size distribution, ZP and EE for the development of drug-loaded LUVs intended for nose-to-brain targeted drug delivery.

We are currently testing several drugs with different lipophilicity as well as charge to confirm the applicability of proposed approach. 


\section{Conclusions}

Drug release from LUVs was significantly affected by the ionic strengths of the external environment confirmed by both linear (zero order) and non-linear (Korsmeyer-Peppas) regression models. Korsmeyer-Peppas model was proven to be suitable to analyse all drug transport data obtained in this study, providing important information on the release mechanism from the carrier in addition to being time efficient (less controls needed) unlike the zero order approximation. The drug release from LUVs could be tailored by the incorporation of cholesterol, and LUVs with $11 \% \mathrm{w} / \mathrm{w}$ cholesterol seemed to be the optimal liposomal composition in terms of stability and responsiveness to osmotic stress. In spite of the fact that regenerated cellulose is considered to be a standard, simpler and cheaper barrier used for the transport study, the Permeapad ${ }^{\circledR}$ appeared a more reliable when it comes to in vitro-in vivo correlation due to closer similarities to biological membranes. The results obtained in this work are rather relevant as the data can be utilized for the development of liposomal formulations intended for nose-to-brain targeted drug delivery.

\section{Acknowledgements}

The authors are grateful to Lipoid $\mathrm{GmbH}$ (Ludwigshafen, Germany) and InnoME

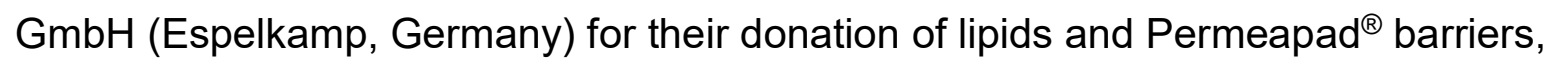
respectively. This project was financed by the University of Troms $\varnothing$ The Arctic University of Norway. This research did not involve funding from any specific grant in the public, commercial, or not-for-profit sectors.

\section{Conflict of interest}

No conflict of interest are declared by the authors.

\section{Appendix. Supplementary data}

Supplementary data to this article can be found online. 


\section{References}

Ahumada, M., Calderon, C., Alvarez, C., Lanio, M. E. \& Lissi, E. A. 2015. Response of unilamellar DPPC and DPPC:SM vesicles to hypo and hyper osmotic shocks: A comparison. Chem Phys Lipids, 188, 54-60.

https://doi.org/10.1016/j.chemphyslip.2015.05.001.

Alam shibly, Sayed u., Ghatak, C., Sayem karal, Mohammad a., Moniruzzaman, M. \& Yamazaki, M. 2016. Experimental estimation of membrane tension induced by osmotic pressure. Biophys J, 111, 2190-2201.

https://doi.org/10.1016/j.bpj.2016.09.043.

Ali, M. H., Kirby, D. J., Mohammed, A. R. \& Perrie, Y. 2010. Solubilisation of drugs within liposomal bilayers: Alternatives to cholesterol as a membrane stabilising agent. J Pharm Pharmacol, 62, 1646-55. https://doi.org/10.1111/j.2042-7158.2010.01090.x.

Allen, T. M. \& Cullis, P. R. 2013. Liposomal drug delivery systems: from concept to clinical applications. Adv Drug Deliv Rev, 65, 36-48.

http://doi.org/10.1016/j.addr.2012.09.037.

Arumugam, K., Subramanian, G. S., Mallayasamy, S. R., Averineni, R. K., Reddy, M. S. \& Udupa, N. 2008. A study of rivastigmine liposomes for delivery into the brain through intranasal route. Acta Pharm, 58, 287-297. https://doi.org/10.2478/v10007008-0014-3.

Bangham, A. D., De Gier, J. \& Greville, G. D. 1967. Osmotic properties and water permeability of phospholipid liquid crystals. Chem Phys Lipids, 1, 225-246. https://doi.org/10.1016/0009-3084(67)90030-8.

Bangham, A. D. \& Horne, R. W. 1964. Negative staining of phospholipids and their structural modification by surface-active agents as observed in the electron microscope. J Mol Biol, 8, 660-8. https://doi.org/10.1016/S0022-2836(64)80115-7. 
Bartels, C., Franks, R., Rybar, S., Schierach, M. \& Wilf, M. 2005. The effect of feed ionic strength on salt passage through reverse osmosis membranes. Desalination, 184, 185-195. https://doi.org/10.1016/j.desal.2005.04.032.

Benavente, J. 1984. A study of membrane potentials across a cellophane membrane for different electrolytes. J Non-Equilib Thermodyn, 9, 217-224. https://doi.org/10.1515/jnet.1984.9.3.217.

Bourganis, V., Kammona, O., Alexopoulos, A. \& Kiparissides, C. 2018. Recent advances in carrier mediated nose-to-brain delivery of pharmaceutics. Eur $\mathrm{J}$ Pharm Biopharm, 128, 337-362. https://doi.org/10.1016/j.ejpb.2018.05.009.

Brandl, M., Eide Flaten, G., Bauer-Brandl, A. \& Begley, T. P. 2007. Passive diffusion across membranes. Wiley Encyclopedia of Chemical Biology. John Wiley \& Sons, Inc.

Briuglia, M. L., Rotella, C., Mcfarlane, A. \& Lamprou, D. A. 2015. Influence of cholesterol on liposome stability and on in vitro drug release. Drug Deliv Trans/ Res, 5, 231-42. https://doi.org/10.1007/s13346-015-0220-8.

Brodin, B., Steffansen, B. \& Uhd Nielsen, C. 2010. Chapter 3.2 Passive diffusion of drug substances: The concepts of flux and permeability. Molecular biopharmaceutics: Aspects of drug characterisation, drug delivery and dosage form evaluation. London: Pharmaceutical Press, 135-152.

Costa, P. \& Sousa Lobo, J. M. 2001. Modeling and comparison of dissolution profiles. Eur J Pharm Sci, 13, 123-133. https://doi.org/10.1016/S0928-0987(01)00095-1.

Di Cagno, M. \& Bauer-Brandl, A. 2014. Assembly for assessing drug permeability with adjustable biomimetic properties. WO 2016/078667 A1.

Di Cagno, M., Bibi, H. A. \& Bauer-Brandl, A. 2015. New biomimetic barrier Permeapad ${ }^{\mathrm{TM}}$ for efficient investigation of passive permeability of drugs. Eur J Pharm Sci, 73, 29-34. https://doi.org/10.1016/j.ejps.2015.03.019. 
Di Cagno, M. P. \& Stein, P. C. 2019. Studying the effect of solubilizing agents on drug diffusion through the unstirred water layer (UWL) by localized spectroscopy. Eur J Pharm Biopharm, 139, 205-212. https://doi.org/10.1016/j.ejpb.2019.04.005.

Fadda, A. M., Baroli, B. M., Maccioni, A. M., Sinico, C., Valenti, D. \& Alhaique, F. 1998. Phospholipid-detergent systems: Effects of polysorbates on the release of liposomal caffeine. Farmaco, 53, 650-654. https://doi.org/10.1016/S0014827X(98)00081-0.

Flaten, G. E., Dhanikula, A. B., Luthman, K. \& Brandl, M. 2006. Drug permeability across a phospholipid vesicle based barrier: A novel approach for studying passive diffusion. Eur J Pharm Sci, 27, 80-90. https://doi.org/10.1016/j.ejps.2005.08.007.

Fujiwara, K. \& Yanagisawa, M. 2014. Generation of giant unilamellar liposomes containing biomacromolecules at physiological intracellular concentrations using hypertonic conditions. ACS Synth Biol, 3, 870-4. https://doi.org/10.1021/sb4001917.

Grit, M. \& Crommelin, D. J. A. 1993. Chemical stability of liposomes: Implications for their physical stability. Chem Phys Lipids, 64, 3-18. https://doi.org/10.1016/00093084(93)90053-6.

Haghiralsadat, F., Amoabediny, G., Helder, M. N., Naderinezhad, S., Sheikhha, M. H., Forouzanfar, T. \& Zandieh-Doulabi, B. 2018. A comprehensive mathematical model of drug release kinetics from nano-liposomes, derived from optimization studies of cationic PEGylated liposomal doxorubicin formulations for drug-gene delivery. Artif Cells Nanomed Biotechnol, 46, 169-177. https://doi.org/10.1080/21691401.2017.1304403.

Homer, J. J., Dowley, A. C., Condon, L., El-Jassar, P. \& Sood, S. 2000. The effect of hypertonicity on nasal mucociliary clearance. Clin Otolaryngol Allied Sci, 25, 558-560. https://doi.org/10.1046/j.1365-2273.2000.00420.x. 
Illum, L. 2007. Nanoparticulate systems for nasal delivery of drugs: A real improvement over simple systems? J Pharm Sci, 96, 473-83.

https://doi.org/10.1002/jps.20718.

Jain, A. \& Jain, S. K. 2016. In vitro release model fitting of liposomes: An insight. Chem Phys Lipids, 201, 28-40. https://doi.org/10.1016/j.chemphyslip.2016.10.005.

Lai, F., Fadda, A. M. \& Sinico, C. 2013. Liposomes for brain delivery. Expert Opin Drug Deliv, 10, 1003-1022. https://doi.org/10.1517/17425247.2013.766714.

Leite, N. B., Martins, D. B., Fazani, V. E., Vieira, M. R. \& Dos Santos Cabrera, M. P. 2018. Cholesterol modulates curcumin partitioning and membrane effects. Biochim Biophys Acta Biomembr, 1860, 2320-2328. https://doi.org/10.1016/j.bbamem.2018.05.018.

Li, M., Du, C., Guo, N., Teng, Y., Meng, X., Sun, H., Li, S., Yu, P. \& Galons, H. 2019. Composition design and medical application of liposomes. Eur J Med Chem, 164, 640-653. https://doi.org/10.1016/j.ejmech.2019.01.007.

Milon, A., Lazrak, T., Albrecht, A.-M., Wolff, G., Weill, G., Ourisson, G. \& Nakatani, Y. 1986. Osmotic swelling of unilamellar vesicles by the stopped-flow light scattering method. Influence of vesicle size, solute, temperature, cholesterol and three $\alpha, \omega-$ dihydroxycarotenoids. Biochim Biophys Acta Biomembr, 859, 1-9. https://doi.org/10.1016/0005-2736(86)90311-1.

Mohammed, A. R., Weston, N., Coombes, A. G. A., Fitzgerald, M. \& Perrie, Y. 2004. Liposome formulation of poorly water soluble drugs: Optimisation of drug loading and ESEM analysis of stability. Int $J$ Pharm, 285, 23-34.

https://doi.org/10.1016/j.jpharm.2004.07.010.

Mui, B. L., Cullis, P. R., Evans, E. A. \& Madden, T. D. 1993. Osmotic properties of large unilamellar vesicles prepared by extrusion. Biophys J, 64, 443-453. http://doi.org/10.1016/S0006-3495(93)81385-7. 
New, R. R. C. 1990. Chapter 1: Introduction. Liposomes: A practical approach. Oxford: IRL Press, 58, 1-32.

Nothnagel, L. \& Wacker, M. G. 2018. How to measure release from nanosized carriers? Eur J Pharm Sci, 120, 199-211. https://doi.org/10.1016/j.ejps.2018.05.004.

Ohno, M., Hamada, T., Takiguchi, K. \& Homma, M. 2009. Dynamic behavior of giant liposomes at desired osmotic pressures. Langmuir, 25, 11680-5.

https://doi.org/10.1021/la900777g.

Ohwaki, T., Ando, H., Kakimoto, F., Uesugi, K., Watanabe, S., Miyake, Y. \& Kayano, M. 1987. Effects of dose, $\mathrm{pH}$, and osmolarity on nasal absorption of secretin in rats II: Histological aspects of the nasal mucosa in relation to the absorption variation due to the effects of $\mathrm{pH}$ and osmolarity. J Pharm Sci, 76, 695-698. https://doi.org/10.1002/jps.2600760905.

Paula, S., Volkov, A. G., Van Hoek, A. N., Haines, T. H. \& Deamer, D. W. 1996. Permeation of protons, potassium ions, and small polar molecules through phospholipid bilayers as a function of membrane thickness. Biophys J, 70, 339-48. https://doi.org/10.1016/s0006-3495(96)79575-9.

Pedersen, P. S., Braunstein, T. H., Jorgensen, A., Larsen, P. L., Holstein-Rathlou, N. H. \& Frederiksen, O. 2007. Stimulation of aquaporin-5 and transepithelial water permeability in human airway epithelium by hyperosmotic stress. Pflugers Arch, 453, 777-85. https://doi.org/10.1007/s00424-006-0157-3.

Pencer, J., White, G. F. \& Hallett, F. R. 2001. Osmotically induced shape changes of large unilamellar vesicles measured by dynamic light scattering. Biophys J, 81, 271628. https://doi.org/10.1016/s0006-3495(01)75914-0.

Polozov, I. V., Anantharamaiah, G. M., Segrest, J. P. \& Epand, R. M. 2001. Osmotically induced membrane tension modulates membrane permeabilization by class $L$ amphipathic helical peptides: nucleation model of defect formation. Biophys $J$, 81, 949-59. https://doi.org/10.1016/s0006-3495(01)75753-0. 
Pubchem National Center for Biotechnology Information Compound Database. 2019a. Caffeine, $C I D=2519$ [Online]. Available from:

https://pubchem.ncbi.nlm.nih.gov/compound/2519 [Accessed on: May 14, 2019].

Pubchem National Center for Biotechnology Information Compound Database. 2019b. Ketoprofen, CID=3825 [Online]. Available from:

https://pubchem.ncbi.nlm.nih.gov/compound/3825 [Accessed on: May 14, 2019].

Pubchem National Center for Biotechnology Information Compound Database. 2019c. Rivastigmine, CID=77991 [Online]. Available from:

https://pubchem.ncbi.nlm.nih.gov/compound/77991 [Accessed on: May 14, 2019].

Quraishi, M. S., Jones, N. S. \& Mason, J. 1998. The rheology of nasal mucus: A review. Clin Otolaryngol Allied Sci, 23, 403-413. https://doi.org/10.1046/j.13652273.1998.00172.x.

Schullery, S. E. 1977. Permeability of iodide in multilamellar liposomes modeled by two compartments and a reservoir. Biochim Biophys Acta Biomembr, 468, 238-244. https://doi.org/10.1016/0005-2736(77)90117-1.

Solomon, D., Gupta, N., Mulla, N. S., Shukla, S., Guerrero, Y. A. \& Gupta, V. 2017. Role of in vitro release methods in liposomal formulation development: Challenges and regulatory perspective. Aaps J, 19, 1669-1681. https://doi.org/10.1208/s12248017-0142-0.

Sun, S.-T., Milon, A., Tanaka, T., Ourisson, G. \& Nakatani, Y. 1986. Osmotic swelling of unilamellar vesicles by the stopped-flow light scattering method. Elastic properties of vesicles. Biochim Biophys Acta Biomembranes, 860, 525-530.

http://doi.org/10.1016/0005-2736(86)90549-3.

Tang, J., Srinivasan, S., Yuan, W., Ming, R., Liu, Y., Dai, Z., Noble, C. O., Hayes, M. E., Zheng, N., Jiang, W., Szoka, F. C. \& Schwendeman, A. 2019. Development of a flow-through USP 4 apparatus drug release assay for the evaluation of amphotericin 
B liposome. Eur J Pharm Biopharm, 134, 107-116.

https://doi.org/10.1016/j.ejpb.2018.11.010.

Vieira, D. \& Gamarra, L. 2016. Getting into the brain: Liposome-based strategies for effective drug delivery across the blood-brain barrier. Int J Nanomed, 11, 5381-5414. https://doi.org/10.2147/IJN.S117210.

Wacker, M. G. 2017. Challenges in the drug release testing of next-generation nanomedicines - What do we know? Mater Today Proc, 4, S214-S217. https://doi.org/10.1016/j.matpr.2017.09.189.

Wu, I. Y., Nikolaisen, T. E., Škalko-Basnet, N. \& Di Cagno, M. P. 2019. The hypotonic environmental changes affect liposomal formulations for nose-to-brain targeted drug delivery. J Pharm Sci. https://doi.org/10.1016/j.xphs.2019.03.006.

Wu, I. Y., Škalko-Basnet, N. \& Di Cagno, M. P. 2017. Influence of the environmental tonicity perturbations on the release of model compounds from large unilamellar vesicles (LUVs): A mechanistic investigation. Colloids Surf B, 157, 65-71. https://doi.org/10.1016/j.colsurfb.2017.05.062.

Xie, Y., Shao, N., Jin, Y., Zhang, L., Jiang, H., Xiong, N., Su, F. \& Xu, H. 2018. Determination of non-liposomal and liposomal doxorubicin in plasma by LC-MS/MS coupled with an effective solid phase extraction: In comparison with ultrafiltration technique and application to a pharmacokinetic study. J Chromatogr B, 1072, 149160. https://doi.org/10.1016/j.jchromb.2017.11.020.

Yuan, W., Kuai, R., Dai, Z., Yuan, Y., Zheng, N., Jiang, W., Noble, C., Hayes, M., Szoka, F. C. \& Schwendeman, A. 2017. Development of a flow-through USP-4 apparatus drug release assay to evaluate doxorubicin liposomes. Aaps J, 19, 150160. https://doi.org/10.1208/s12248-016-9958-2.

Zhu, C., Jiang, L., Chen, T.-M. \& Hwang, K.-K. 2002. A comparative study of artificial membrane permeability assay for high throughput profiling of drug absorption 
potential. Eur J Med Chem, 37, 399-407. https://doi.org/10.1016/S02235234(02)01360-0. 


\section{List of figures}

\section{Graphical abstract}

Fig. 1: Schematic representation of the in vitro diffusion study using the dynamic dialysis method. The amount of drug accumulated in the acceptor compartment is directly influenced by the drug release rate from liposome $\left(\mathrm{K}^{\mathrm{l}}\right)$ and the drug transport rate through a diffusion barrier $(\mathrm{K})$. The mechanism of drug release from liposomes can be defined by the transport exponent (n), obtained from the order of the fitted curve according to the Korsmeyer-Peppas equation.

Fig. 2: In vitro diffusion study of caffeine $(\circ)$ and hydrocortisone $(\Delta)$ from solutions (filled symbols) and LUV dispersions (0\% w/w cholesterol, empty symbols) through regenerated cellulose (a) or, alternatively, Permeapad ${ }^{\circledR}$ (b) as barriers in isotonic conditions. Results represent the mean \pm standard deviation $\left(n=3,{ }^{*} p \leq 0.050\right.$, $\left.{ }^{* *} p \leq 0.010,{ }^{* * *} p \leq 0.001\right)$.

Fig. 3: Resistance to drug transport through liposomal bilayers $\left(R_{L}\right)$ containing various amount of cholesterol $(0,11$ and $25 \% \mathrm{w} / \mathrm{w})$ for caffeine (a) or hydrocortisone (b). Diffusion experiments were carried out employing regenerated cellulose (white bars) or, alternatively, Permeapad ${ }^{\circledR}$ (grey bars) barriers and exposing the LUV dispersions to isotonic, hypotonic and hypertonic environments (tonicity difference of 0 and \pm 300 $\mathrm{mOsm} / \mathrm{kg}$ within inner core of liposomes and external environment), respectively. Results represent the mean \pm standard deviation $\left(n=3,{ }^{*} p \leq 0.050,{ }^{* *} p \leq 0.010\right.$, $\left.{ }^{* * *} p \leq 0.001\right)$.

Fig. 4: Transport constant $(K)$ obtained from non-linear data fitting of diffusion experimental data for caffeine- (a) or hydrocortisone- (b) LUV dispersions with various amount of cholesterol incorporated in the phospholipid bilayer $(0,11$ and $25 \% \mathrm{w} / \mathrm{w})$. Diffusion experiments were carried out employing regenerated cellulose (white bars) or alternatively, Permeapad ${ }^{\circledR}$ (grey bars) as barriers. LUV formulations were exposed to isotonic, hypotonic, and hypertonic environments (tonicity difference between inner core and external environment of liposomes of 0 and $\pm 300 \mathrm{mOsm} / \mathrm{kg}$ ), respectively. 
Results represent the mean \pm standard deviation $\left(n=3,{ }^{*} p \leq 0.050,{ }^{* *} p \leq 0.010\right.$, $\left.{ }^{* * *} p \leq 0.001\right)$.

Fig. 5: Transport exponent ( $n$ ) obtained from non-linear data fitting of diffusion experimental results for caffeine-(a) or hydrocortisone- (b) LUV dispersions with various amount of cholesterol incorporated in the phospholipid bilayer $(0,11$ and $25 \% \mathrm{w} / \mathrm{w}$ ). Diffusion experiments were carried out employing regenerated cellulose (white bars) or, alternatively, Permeapad ${ }^{\circledR}$ (grey bars) as barriers. LUV formulations were exposed to isotonic, hypotonic, and hypertonic environments (tonicity difference between inner core and external environment of liposomes of 0 and $\pm 300 \mathrm{mOsm} / \mathrm{kg}$ ), respectively. Results represent the mean \pm standard deviation $\left(n=3,{ }^{*} p \leq 0.050\right.$, $\left.{ }^{* *} p \leq 0.010,{ }^{* * *} p \leq 0.001\right)$. 


\section{List of tables}

Table 1: Experimentally determined osmolality and $\mathrm{pH}$ for all LUV dispersions and PBS solutions used in the in vitro study. Results represent mean \pm standard deviation $(n=2)$.

Table 2: Measured size (average diameter), polydispersity index (PI), $\zeta$-potential (ZP) and entrapment efficiency (EE) for LUV dispersions used in the in vitro release study. Results represent mean \pm standard deviation $(n=2)$.

Table 3: Liposomes characteristics under storage at 6 and $22^{\circ} \mathrm{C}$ over a period of 65 days. Changes were monitored by measuring the tonicity of the LUV dispersions (osmolality), liposomal size (average diameter), polydispersity index (PI), $\zeta$-potential $(\mathrm{ZP})$, and entrapment efficiency (EE). Results represent mean \pm standard deviation $(n=2)$. 


\section{List of supplementary figures}

Fig.A.1: Fitting of caffeine diffusion experimental results to the Korsmeyer-Peppas model. Diffusion experiments were carried out employing regenerated cellulose (a) or alternatively, Permeapad ${ }^{\circledR}$ (b) as the barriers. The drugs were formulated in LUV dispersions with various amount of cholesterol incorporated in the phospholipid bilayers $(0,11$ and $25 \% \mathrm{w} / \mathrm{w})$ and the LUV dispersions were exposed to isotonic, hypotonic and hypertonic environments (tonicity difference of 0 and $\pm 300 \mathrm{mOsm} / \mathrm{kg}$ within inner core of liposomes and external environment). Results represent the mean \pm standard deviation of three parallel experiments $\left(n=3,{ }^{*} p \leq 0.050,{ }^{* *} p \leq 0.010\right.$, $\left.{ }^{* * *} p \leq 0.001\right)$.

Fig.A.2: Fitting of hydrocortisone diffusion experiment results to the KorsmeyerPeppas model. Diffusion experiments were carried out employing regenerated cellulose (a) or alternatively, Permeapad ${ }^{\circledR}(b)$ as barriers. The drugs were formulated in LUV dispersions with various amount of cholesterol incorporated in the phospholipid bilayers $(0,11$ and $25 \% \mathrm{w} / \mathrm{w})$ and the LUV dispersions were exposed to isotonic, hypotonic and hypertonic environments (tonicity difference of 0 and $\pm 300 \mathrm{mOsm} / \mathrm{kg}$ within inner core of liposomes and external environment). Results represent the mean \pm standard deviation of three parallel experiments $\left(n=3,{ }^{*} p \leq 0.050,{ }^{* *} p \leq 0.010\right.$, $\left.{ }^{* * *} p \leq 0.001\right)$.

Fig.B.1: Photographs of LUV-dispersions with caffeine (a) or hydrocortisone (b) and various amount of cholesterol incorporated in the phospholipid bilayers $(0,11$ and $25 \%$ $\mathrm{w} / \mathrm{w}$ ) after 65 days storage at 6 and $22^{\circ} \mathrm{C}$. Each tube present one replicate out of total two replicates $(n=2)$. 


\section{Tables}

Table 1: Experimentally determined osmolality and $\mathrm{pH}$ for all LUV dispersions and PBS solutions used in the in vitro study. Results represent mean \pm standard deviation $(n=2)$.

\begin{tabular}{|c|c|c|c|c|c|}
\hline LUVs & $\begin{array}{c}\text { Cholesterol } \\
\text { (\% of lipid } \\
\text { weight) }\end{array}$ & $\begin{array}{c}\text { Initial LUVs } \\
\text { osmolality } \\
\text { (mOsm/kg) }\end{array}$ & $\begin{array}{l}\text { Buffer } \\
\text { type }\end{array}$ & $\begin{array}{c}\text { PBS } \\
\text { osmolality } \\
\text { (mOsm) }\end{array}$ & $\begin{array}{c}\text { PBS } \\
\text { pH }\end{array}$ \\
\hline \multirow{9}{*}{ Caffeine } & \multirow{3}{*}{ (noryo } & \multirow{3}{*}{$420 \pm 11$} & PBShypo & $119 \pm 10$ & $7.5 \pm 0.1$ \\
\hline & & & PBSiso & $418 \pm 10$ & $7.3 \pm 0.0$ \\
\hline & & & PBShyper & $718 \pm 12$ & $7.2 \pm 0.0$ \\
\hline & \multirow{3}{*}{11} & \multirow{3}{*}{$392 \pm 12$} & PBShypo & $95 \pm 16$ & $7.6 \pm 0.0$ \\
\hline & & & PBSiso & $386 \pm 5$ & $7.3 \pm 0.0$ \\
\hline & & & PBShyper & $693 \pm 23$ & $7.2 \pm 0.0$ \\
\hline & \multirow{3}{*}{25} & \multirow{3}{*}{$388 \pm 4$} & PBShypo & $88 \pm 8$ & $7.5 \pm 0.0$ \\
\hline & & & PBSiso & $393 \pm 4$ & $7.3 \pm 0.0$ \\
\hline & & & PBShyper & $692 \pm 8$ & $7.2 \pm 0.0$ \\
\hline \multirow{9}{*}{ Hydrocortisone } & \multirow{3}{*}{$0^{\mathrm{a}}$} & \multirow{3}{*}{$383 \pm 5$} & PBShypo & $83 \pm 5$ & $7.6 \pm 0.0$ \\
\hline & & & PBSiso & $384 \pm 5$ & $7.3 \pm 0.0$ \\
\hline & & & PBShyper & $683 \pm 5$ & $7.2 \pm 0.0$ \\
\hline & \multirow{3}{*}{11} & \multirow{3}{*}{$405 \pm 5$} & PBShypo & $105 \pm 5$ & $7.6 \pm 0.0$ \\
\hline & & & PBSiso & $405 \pm 5$ & $7.3 \pm 0.0$ \\
\hline & & & PBShyper & $705 \pm 5$ & $7.2 \pm 0.0$ \\
\hline & \multirow{3}{*}{25} & \multirow{3}{*}{$383 \pm 19$} & PBShypo & $86 \pm 16$ & $7.6 \pm 0.0$ \\
\hline & & & PBSiso & $385 \pm 16$ & $7.3 \pm 0.0$ \\
\hline & & & PBShyper & $687 \pm 15$ & $7.2 \pm 0.0$ \\
\hline
\end{tabular}

$\overline{a_{n}=3}$

Table 2: Measured size (average diameter), polydispersity index (PI), $\zeta$-potential (ZP) and entrapment efficiency (EE) for LUV dispersions used in the in vitro release study. Results represent mean \pm standard deviation $(n=2)$.

\begin{tabular}{|c|c|c|c|c|c|}
\hline LUVs & $\begin{array}{l}\text { Cholesterol } \\
\text { (\% of lipid } \\
\text { weight) }\end{array}$ & $\begin{array}{l}\text { Size } \\
(\mathrm{nm})\end{array}$ & PI & $\begin{array}{l}\mathrm{ZP} \\
(\mathrm{mV})\end{array}$ & $\begin{array}{l}\mathrm{EE} \\
(\%)\end{array}$ \\
\hline \multirow{3}{*}{ Caffeine } & 0 & $236 \pm 36$ & $0.25 \pm 0.02$ & $-3.7 \pm 1.0$ & $12 \pm 1$ \\
\hline & 11 & $289 \pm 55^{*}$ & $\begin{array}{l}0.34 \pm \\
0.04^{*}\end{array}$ & $-3.0 \pm 1.0$ & $11 \pm 2$ \\
\hline & 25 & $\begin{array}{l}374 \pm \\
80^{* * *}\end{array}$ & $\begin{array}{l}0.45 \pm \\
0.05^{\star * *}\end{array}$ & $-3.5 \pm 1.1$ & $10 \pm 1^{* * *}$ \\
\hline \multirow[b]{2}{*}{ Hydrocortisone } & $\begin{array}{l}0^{a} \\
11\end{array}$ & $\begin{array}{l}246 \pm 30 \\
248+38\end{array}$ & $\begin{array}{l}0.25 \pm 0.01 \\
0.24 \pm 0.02\end{array}$ & $\begin{array}{l}-3.5 \pm 1.0 \\
-41+1.1\end{array}$ & $\begin{array}{c}68 \pm 5 \\
60 \pm 3^{* * *}\end{array}$ \\
\hline & 25 & $261 \pm 47$ & $\begin{array}{l}0.35 \pm \\
0.03^{\star * *}\end{array}$ & $-5.2 \pm 1.1$ & $51 \pm 3^{\star * *}$ \\
\hline
\end{tabular}


Table 3: Liposomes characteristics under storage at 6 and $22^{\circ} \mathrm{C}$ over a period of 65 days. Changes were monitored by measuring the tonicity of the LUV dispersions (osmolality), liposomal size (average diameter), polydispersity index (PI), $\zeta$-potential (ZP), and entrapment efficiency (EE). Results represent mean \pm standard deviation $(n=2)$.

\begin{tabular}{|c|c|c|c|c|c|c|c|c|c|c|c|c|}
\hline \multirow[b]{2}{*}{ LUVs } & \multirow[b]{2}{*}{$\begin{array}{c}\text { Cholestero } \\
\text { I (\% w/w) }\end{array}$} & \multirow[b]{2}{*}{$\begin{array}{c}\mathrm{Da} \\
\mathbf{y}\end{array}$} & \multicolumn{5}{|c|}{$6^{\circ} \mathrm{C}$} & \multicolumn{5}{|c|}{$22^{\circ} \mathrm{C}$} \\
\hline & & & $\begin{array}{c}\text { Osmolal } \\
\text { ity } \\
\text { (mOsm/ } \\
\text { kg) }\end{array}$ & $\begin{array}{l}\text { Size } \\
(\mathrm{nm})\end{array}$ & PI & $\begin{array}{c}\mathrm{ZP} \\
(\mathrm{mV})\end{array}$ & EE & $\begin{array}{c}\text { Osmola } \\
\text { lity } \\
\text { (mOsm/ } \\
\text { kg) }\end{array}$ & $\begin{array}{l}\text { Size } \\
(\mathrm{nm})\end{array}$ & PI & $\begin{array}{c}\mathrm{ZP} \\
(\mathrm{mV})\end{array}$ & EE \\
\hline \multirow{12}{*}{ Caffeine } & \multirow{4}{*}{0} & 3 & $400 \pm 0$ & $255 \pm 41$ & $\begin{array}{c}0.27 \pm \\
0.03\end{array}$ & $\begin{array}{c}-2.7 \pm \\
0.9\end{array}$ & $13 \pm 1$ & - & - & - & - & - \\
\hline & & 14 & $398 \pm 5$ & $266 \pm 44$ & $\begin{array}{c}0.28 \pm \\
0.03\end{array}$ & $\begin{array}{c}-2.1 \pm \\
0.8^{*}\end{array}$ & $14 \pm 0$ & $400 \pm 0$ & $\begin{array}{c}245 \pm \\
36\end{array}$ & $\begin{array}{c}0.23 \pm \\
0.02\end{array}$ & $\begin{array}{l}-6.5 \pm \\
1.0^{* * *}\end{array}$ & $15 \pm 1^{*}$ \\
\hline & & 35 & $395 \pm 6$ & $291 \pm 52$ & $\begin{array}{c}0.30 \pm \\
0.03\end{array}$ & $\begin{array}{c}-3.2 \pm \\
0.9^{*}\end{array}$ & $15 \pm 0$ * & $403 \pm 5$ & $\begin{array}{c}318 \pm \\
60^{* *}\end{array}$ & $\begin{array}{c}0.34 \pm \\
0.04^{*}\end{array}$ & $\begin{array}{c}-14.7 \pm \\
1.4^{* * *}\end{array}$ & $31 \pm 6^{* *}$ \\
\hline & & 65 & $390 \pm 12$ & $266 \pm 43$ & $\begin{array}{c}0.29 \pm \\
0.03\end{array}$ & $\begin{array}{l}-6.2 \pm \\
1.0^{* * *}\end{array}$ & $13 \pm 2$ & $405 \pm 6$ & $\begin{array}{l}158 \pm \\
28^{* * *}\end{array}$ & $\begin{array}{l}0.34 \pm \\
0.03^{*}\end{array}$ & $\begin{array}{c}-43.1 \pm \\
1.2^{* * *}\end{array}$ & $\begin{array}{l}40 \pm \\
5^{\star \star *}\end{array}$ \\
\hline & \multirow{4}{*}{11} & 3 & $376 \pm 6$ & $381 \pm 82$ & $\begin{array}{c}0.48 \pm \\
0.05\end{array}$ & $\begin{array}{c}-3.1 \pm \\
1.0\end{array}$ & $9 \pm 1$ & - & - & - & - & - \\
\hline & & 14 & $375 \pm 9$ & $342 \pm 69$ & $\begin{array}{c}0.39 \pm \\
0.04^{*}\end{array}$ & $\begin{array}{c}-4.4 \pm \\
1.0^{* *}\end{array}$ & $13 \pm 1^{* * *}$ & $\begin{array}{c}374 \pm \\
10\end{array}$ & $\begin{array}{c}318 \pm \\
62^{*}\end{array}$ & $\begin{array}{c}0.41 \pm \\
0.04\end{array}$ & $\begin{array}{l}-10.0 \pm \\
1.23^{\star * *}\end{array}$ & $16 \pm 2^{* * *}$ \\
\hline & & 35 & $374 \pm 8$ & $358 \pm 75$ & $\begin{array}{c}0.43 \pm \\
0.04\end{array}$ & $\begin{array}{l}-7.7 \pm \\
1.3^{* * *}\end{array}$ & $16 \pm 3^{* \star *}$ & $365 \pm 9$ & $\begin{array}{c}302 \pm \\
58^{* *}\end{array}$ & $\begin{array}{l}0.38 \pm \\
0.04^{*}\end{array}$ & $\begin{array}{l}-9.0 \pm \\
1.2^{* * *}\end{array}$ & $\begin{array}{l}20 \pm \\
1^{* * *}\end{array}$ \\
\hline & & 65 & $364 \pm 8^{*}$ & $350 \pm 73$ & $\begin{array}{c}0.46 \pm \\
0.04\end{array}$ & $\begin{array}{c}-10.7 \pm \\
1.3^{* * *}\end{array}$ & $16 \pm 4^{* * *}$ & $\begin{array}{c}360 \pm \\
4^{* *}\end{array}$ & $\begin{array}{c}313 \pm \\
62^{*}\end{array}$ & $\begin{array}{c}0.37 \pm \\
0.04^{*}\end{array}$ & $\begin{array}{c}-19.3 \pm \\
1.3^{* * *}\end{array}$ & $\begin{array}{l}30 \pm \\
5^{* * *}\end{array}$ \\
\hline & \multirow{4}{*}{25} & 3 & $398 \pm 21$ & $373 \pm 82$ & $\begin{array}{c}0.48 \pm \\
0.05\end{array}$ & $\begin{array}{c}-4.9 \pm \\
1.0\end{array}$ & $10 \pm 1$ & - & - & - & - & - \\
\hline & & 14 & $395 \pm 24$ & $382 \pm 83$ & $\begin{array}{c}0.48 \pm \\
0.05\end{array}$ & $\begin{array}{c}-5.0 \pm \\
1.1\end{array}$ & $11 \pm 1$ & $\begin{array}{c}390 \pm \\
18\end{array}$ & $\begin{array}{c}339 \pm \\
67\end{array}$ & $\begin{array}{c}0.43 \pm \\
0.04\end{array}$ & $\begin{array}{l}-9.5 \pm \\
1.3^{* * *}\end{array}$ & $12 \pm 1^{*}$ \\
\hline & & 35 & $390 \pm 23$ & $387 \pm 83$ & $\begin{array}{c}0.50 \pm \\
0.05\end{array}$ & $\begin{array}{l}-9.3 \pm \\
1.2^{* * *}\end{array}$ & $11 \pm 1$ & $\begin{array}{c}390 \pm \\
23\end{array}$ & $\begin{array}{c}352 \pm \\
73\end{array}$ & $\begin{array}{c}0.47 \pm \\
0.04\end{array}$ & $\begin{array}{l}-8.4 \pm \\
1.3^{* * *}\end{array}$ & $\begin{array}{l}15 \pm \\
1^{* * *}\end{array}$ \\
\hline & & 65 & $391 \pm 10$ & $327 \pm 68$ & $\begin{array}{c}0.46 \pm \\
0.04\end{array}$ & $\begin{array}{c}-11.1 \pm \\
1.3^{\star \star *}\end{array}$ & $13 \pm 1^{*}$ & $\begin{array}{c}390 \pm \\
12\end{array}$ & $\begin{array}{c}372 \pm \\
80\end{array}$ & $\begin{array}{c}0.48 \pm \\
0.05\end{array}$ & $\begin{array}{l}-9.8 \pm \\
1.2^{* * \star}\end{array}$ & $\begin{array}{l}19 \pm \\
1^{* * *}\end{array}$ \\
\hline
\end{tabular}




\begin{tabular}{|c|c|c|c|c|c|c|c|c|c|c|c|c|}
\hline \multirow{12}{*}{ Hydrocortisone } & \multirow{4}{*}{0} & 3 & $365 \pm 17$ & $238 \pm 33$ & $\begin{array}{c}0.21 \pm \\
0.02\end{array}$ & $\begin{array}{c}-3.5 \pm \\
1.0\end{array}$ & $74 \pm 1$ & - & - & - & - & - \\
\hline & & 14 & $370 \pm 12$ & $\begin{array}{c}251 \pm \\
37^{*}\end{array}$ & $\begin{array}{c}0.23 \pm \\
0.02^{*}\end{array}$ & $\begin{array}{c}-5.0 \pm \\
1.1^{* \star *} a\end{array}$ & $71 \pm 1^{\star *}$ & $\begin{array}{c}370 \pm \\
12\end{array}$ & $\begin{array}{c}259 \pm \\
37^{*}\end{array}$ & $\begin{array}{c}0.22 \pm \\
0.02\end{array}$ & $\begin{array}{l}-7.2 \pm \\
1.2^{* * * a}\end{array}$ & $69 \pm 2^{* *}$ \\
\hline & & 35 & $370 \pm 7$ & $\begin{array}{c}291 \pm \\
51^{* *}\end{array}$ & $\begin{array}{l}0.32 \pm \\
0.03^{\star * *}\end{array}$ & $\begin{array}{l}-5.1 \pm \\
1.1^{* * *}\end{array}$ & $70 \pm 1^{\star *}$ & $370 \pm 7$ & $\begin{array}{c}322 \pm \\
59^{* *}\end{array}$ & $\begin{array}{c}0.35 \pm \\
0.03^{\star * *}\end{array}$ & $\begin{array}{l}-5.5 \pm \\
1.1^{* * *}\end{array}$ & $70 \pm 2^{\star *}$ \\
\hline & & 65 & $355 \pm 6$ & $\begin{array}{c}304 \pm \\
57^{* *}\end{array}$ & $\begin{array}{c}0.34 \pm \\
0.04^{\star * *}\end{array}$ & $\begin{array}{l}-7.8 \pm \\
1.1^{* \star *}\end{array}$ & $78 \pm 1^{\star *}$ & $\begin{array}{c}358 \pm \\
21\end{array}$ & $\begin{array}{c}262 \pm \\
41^{* *}\end{array}$ & $\begin{array}{c}0.26 \pm \\
0.02^{*}\end{array}$ & $\begin{array}{l}-6.2 \pm \\
1.1^{\star \star *}\end{array}$ & $71 \pm 2^{*}$ \\
\hline & \multirow{4}{*}{11} & 3 & $410 \pm 18$ & $333 \pm 67$ & $\begin{array}{c}0.41 \pm \\
0.04\end{array}$ & $\begin{array}{c}-4.2 \pm \\
1.0\end{array}$ & $64 \pm 2$ & - & - & - & - & - \\
\hline & & 14 & $415 \pm 6$ & $335 \pm 68$ & $\begin{array}{c}0.41 \pm \\
0.04\end{array}$ & $\begin{array}{l}-5.4 \pm \\
1.1^{* a}\end{array}$ & $61 \pm 1^{*}$ & $\begin{array}{c}418 \pm \\
10\end{array}$ & $\begin{array}{l}260 \pm \\
42^{* * *}\end{array}$ & $\begin{array}{c}0.28 \pm \\
0.03^{* * *}\end{array}$ & $\begin{array}{c}-5.7 \pm \\
1.2^{* a}\end{array}$ & $63 \pm 1$ \\
\hline & & 35 & $410 \pm 12$ & $\begin{array}{c}255 \pm \\
44^{* *}\end{array}$ & $\begin{array}{l}0.29 \pm \\
0.03^{* *}\end{array}$ & $\begin{array}{l}-6.8 \pm \\
1.2^{* * *}\end{array}$ & $63 \pm 1$ & $\begin{array}{c}408 \pm \\
15\end{array}$ & $\begin{array}{c}294 \pm \\
52^{*}\end{array}$ & $\begin{array}{c}0.35 \pm \\
0.03\end{array}$ & $\begin{array}{c}-4.6 \pm \\
1.2\end{array}$ & $65 \pm 1$ \\
\hline & & 65 & $410 \pm 12$ & $\begin{array}{c}283 \pm \\
50^{*}\end{array}$ & $\begin{array}{c}0.34 \pm \\
0.03\end{array}$ & $\begin{array}{l}-8.8 \pm \\
1.2^{* \star *} \\
\end{array}$ & $65 \pm 2$ & $\begin{array}{c}413 \pm \\
10\end{array}$ & $\begin{array}{c}295 \pm \\
55^{*} \\
\end{array}$ & $\begin{array}{c}0.36 \pm \\
0.04\end{array}$ & $\begin{array}{l}-6.7 \pm \\
1.2^{* * *} \\
\end{array}$ & $67 \pm 3$ \\
\hline & \multirow{4}{*}{25} & 3 & $438 \pm 10$ & $330 \pm 66$ & $\begin{array}{c}0.41 \pm \\
0.04\end{array}$ & $\begin{array}{c}-5.4 \pm \\
1.1\end{array}$ & $55 \pm 2$ & - & - & - & - & - \\
\hline & & 14 & $430 \pm 12$ & $\begin{array}{c}386 \pm \\
81^{*}\end{array}$ & $\begin{array}{c}0.48 \pm \\
0.04^{*}\end{array}$ & $\begin{array}{l}-7.8 \pm \\
1.2^{* * a}\end{array}$ & $53 \pm 0$ & $438 \pm 5$ & $\begin{array}{c}358 \pm \\
74\end{array}$ & $\begin{array}{c}0.46 \pm \\
0.04\end{array}$ & $\begin{array}{l}-7.1 \pm \\
1.2^{* * \star a}\end{array}$ & $54 \pm 1$ \\
\hline & & 35 & $423 \pm 10$ & $333 \pm 69$ & $\begin{array}{c}0.43 \pm \\
0.04\end{array}$ & $\begin{array}{c}-5.7 \pm \\
1.3\end{array}$ & $53 \pm 1$ & $428 \pm 10$ & $\begin{array}{c}303 \pm \\
58\end{array}$ & $\begin{array}{c}0.40 \pm \\
0.04\end{array}$ & $\begin{array}{l}-8.8 \pm \\
1.2^{\star \star *}\end{array}$ & $58 \pm 2$ \\
\hline & & 65 & $423 \pm 21$ & $323 \pm 64$ & $\begin{array}{c}0.42 \pm \\
0.04\end{array}$ & $\begin{array}{c}-10.1 \pm \\
1.3^{\star * *}\end{array}$ & $53 \pm 0$ & $423 \pm 5^{*}$ & $\begin{array}{c}382 \pm \\
84^{*}\end{array}$ & $\begin{array}{c}0.51 \pm \\
0.05^{*}\end{array}$ & $\begin{array}{l}-7.6 \pm \\
1.3^{* * *}\end{array}$ & $54 \pm 1$ \\
\hline
\end{tabular}

${ }^{*} p \leq 0.050,{ }^{* *} p \leq 0.010,{ }^{* * *} p \leq 0.001$ when compared to the control (measurement on day 3 ).

aMeasured on day 22 instead of day 14 . 


\section{Figures}

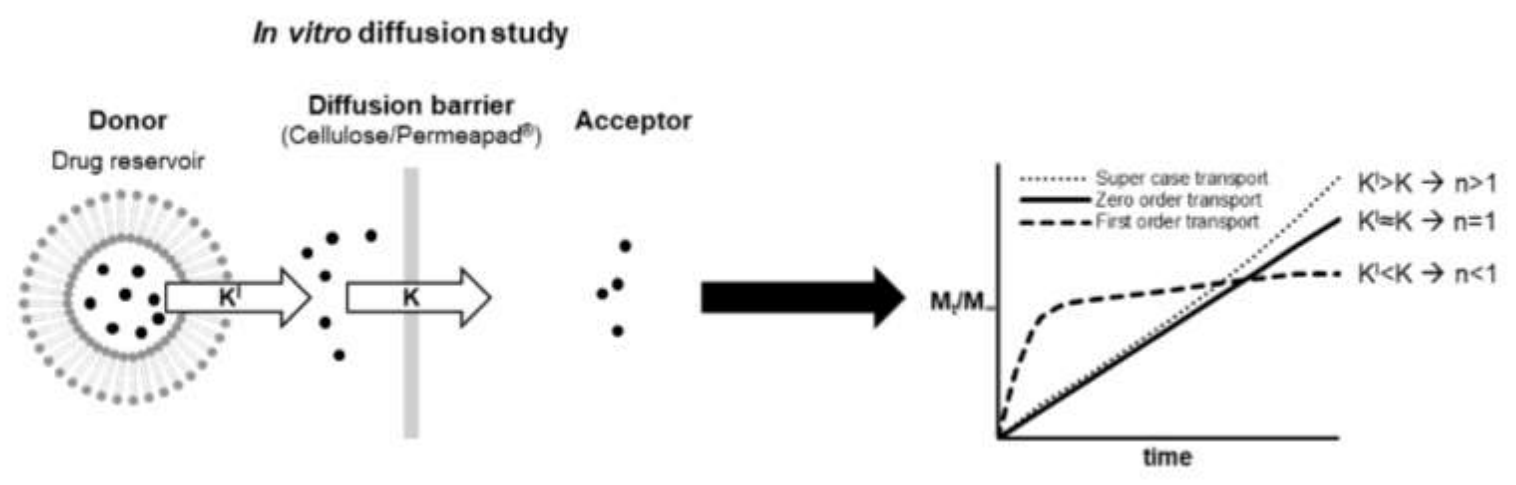

Fig. 1: Schematic representation of the in vitro diffusion study using the dynamic dialysis method. The amount of drug accumulated in the acceptor compartment is directly influenced by the drug release rate from liposome $\left(\mathrm{K}^{\prime}\right)$ and the drug transport rate through a diffusion barrier $(\mathrm{K})$. The mechanism of drug release from liposomes can be defined by the transport exponent (n), obtained from the order of the fitted curve according to the Korsmeyer-Peppas equation. 

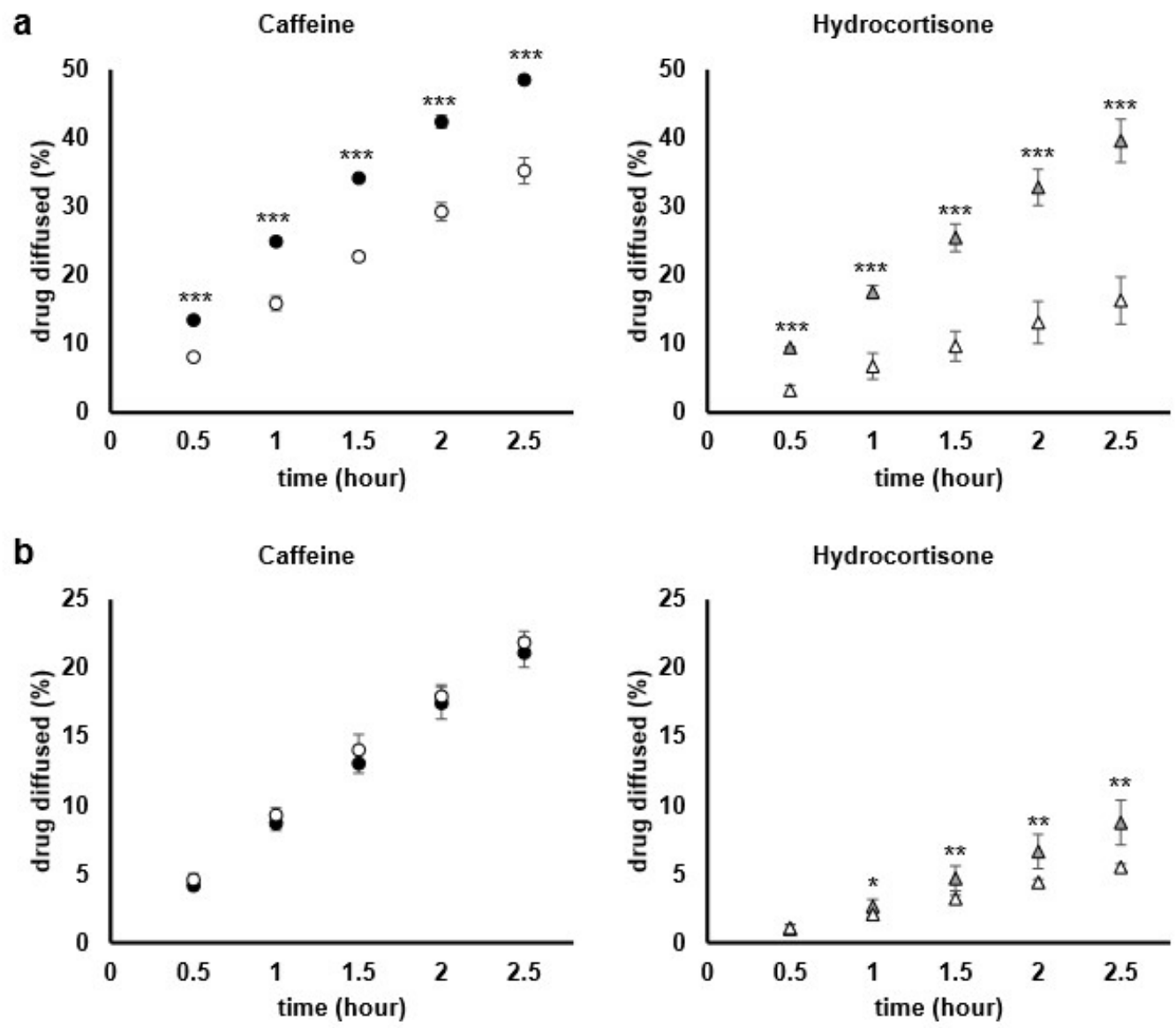

OCaffeine solution

Caffeine-LUVs

$\Delta$ Hydrocortisone solution

$\Delta$ Hydrocortisone-LUVs

Fig. 2: In vitro diffusion study of caffeine $(\circ)$ and hydrocortisone $(\Delta)$ from solutions (filled symbols) and LUV dispersions ( $0 \% \mathrm{w} / \mathrm{w}$ cholesterol, empty symbols) through regenerated cellulose (a) or, alternatively, Permeapad ${ }^{\circledR}$ (b) as barriers in isotonic conditions. Results represent the mean \pm standard deviation $\left(n=3,{ }^{*} p \leq 0.050\right.$, $\left.{ }^{* *} p \leq 0.010,{ }^{* * *} p \leq 0.001\right)$. 

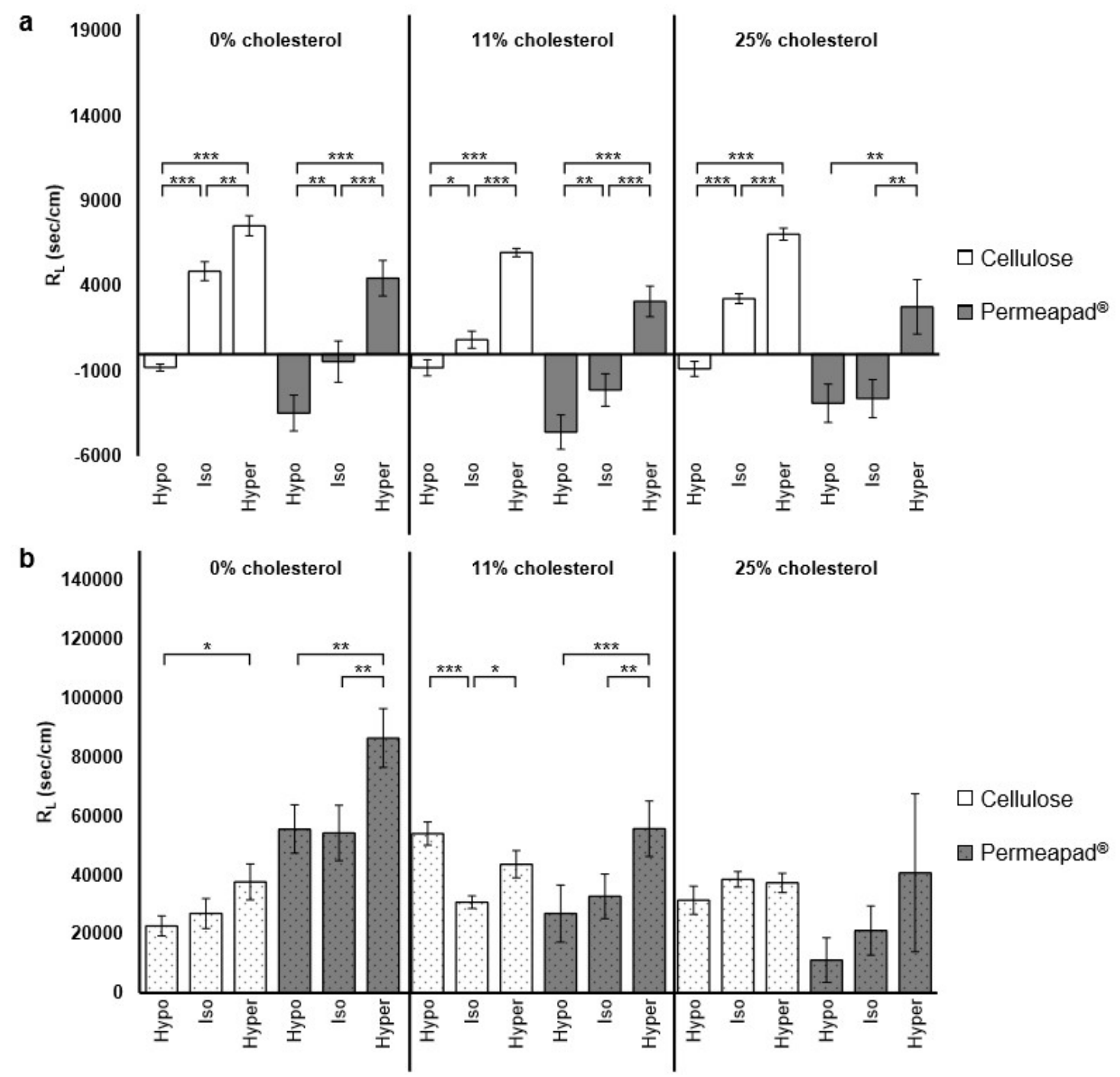

Fig. 3: Resistance to drug transport through liposomal bilayers $\left(R_{\mathrm{L}}\right)$ containing various amount of cholesterol $(0,11$ and $25 \% \mathrm{w} / \mathrm{w})$ for caffeine (a) or hydrocortisone (b). Diffusion experiments were carried out employing regenerated cellulose (white bars) or, alternatively, Permeapad ${ }^{\circledR}$ (grey bars) barriers and exposing the LUV dispersions to isotonic, hypotonic and hypertonic environments (tonicity difference of 0 and \pm 300 $\mathrm{mOsm} / \mathrm{kg}$ within inner core of liposomes and external environment), respectively. Results represent the mean \pm standard deviation $\left(n=3,{ }^{*} p \leq 0.050,{ }^{* *} p \leq 0.010\right.$, $\left.{ }^{* * *} p \leq 0.001\right)$. 



Fig. 4: Transport constant $(K)$ obtained from non-linear data fitting of diffusion experimental data for caffeine- (a) or hydrocortisone- (b) LUV dispersions with various amount of cholesterol incorporated in the phospholipid bilayer $(0,11$ and $25 \% \mathrm{w} / \mathrm{w})$. Diffusion experiments were carried out employing regenerated cellulose (white bars) or alternatively, Permeapad ${ }^{\circledR}$ (grey bars) as barriers. LUV formulations were exposed to isotonic, hypotonic, and hypertonic environments (tonicity difference between inner core and external environment of liposomes of 0 and $\pm 300 \mathrm{mOsm} / \mathrm{kg}$ ), respectively. Results represent the mean \pm standard deviation $\left(n=3,{ }^{*} p \leq 0.050,{ }^{* *} p \leq 0.010\right.$, $\left.{ }^{* * *} p \leq 0.001\right)$. 


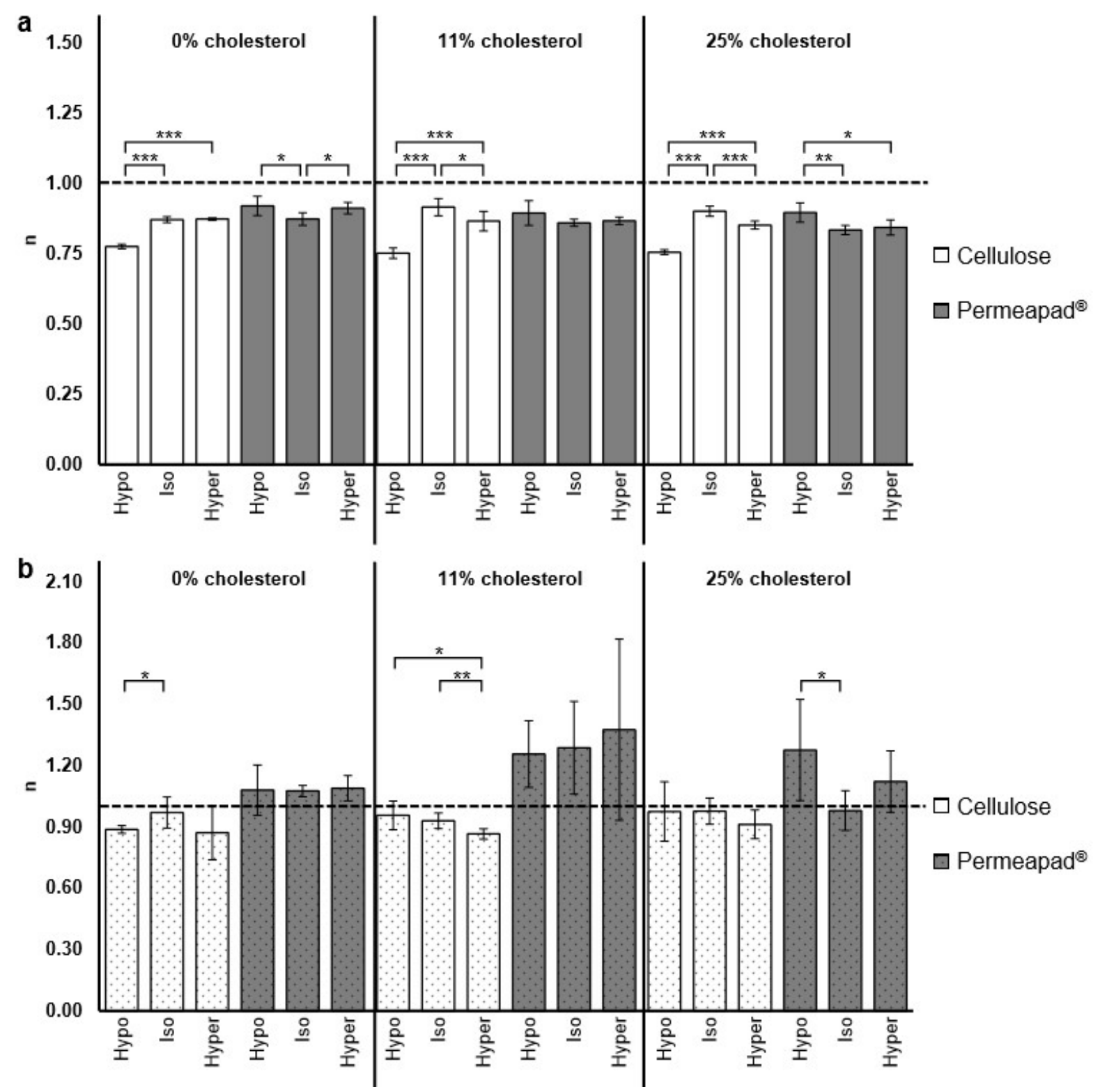

Fig. 5: Transport exponent $(n)$ obtained from non-linear data fitting of diffusion experimental results for caffeine-(a) or hydrocortisone- (b) LUV dispersions with various amount of cholesterol incorporated in the phospholipid bilayer (0, 11 and $25 \% \mathrm{w} / \mathrm{w})$. Diffusion experiments were carried out employing regenerated cellulose (white bars) or, alternatively, Permeapad ${ }^{\circledR}$ (grey bars) as barriers. LUV formulations were exposed to isotonic, hypotonic, and hypertonic environments (tonicity difference between inner core and external environment of liposomes of 0 and $\pm 300 \mathrm{mOsm} / \mathrm{kg}$ ), respectively. Results represent the mean \pm standard deviation $\left(n=3,{ }^{*} p \leq 0.050\right.$, $\left.{ }^{* *} p \leq 0.010,{ }^{* * *} p \leq 0.001\right)$. 
